\title{
Drought in the Eastern Cape region of South Africa and trends in rainfall characteristics
}

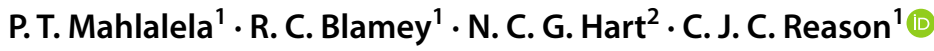

Received: 25 March 2020 / Accepted: 7 August 2020 / Published online: 14 August 2020

(c) Springer-Verlag GmbH Germany, part of Springer Nature 2020

\begin{abstract}
Much of the Eastern Cape province in South Africa has been experiencing a severe drought since 2015. This drought has had major socio-economic effects particularly on the large impoverished rural population as well as on some urban areas where supplied water services have broken down in several cases. The region is influenced by both midlatitude and tropical systems leading to a complex regional meteorology that hitherto has not been much studied compared to other parts of South Africa. Here, the ongoing drought is examined in the context of long-term trends and the interannual rainfall variability of the region. Although the region has experienced drought in all seasons since 2015, focus here is placed on the spring (September-November) which shows the most consistent and robust signal. On average, this season contributes between about 25-35\% of the annual rainfall total. Based on CHIRPS data, it is found that this season shows a significant decreasing trend in both rainfall totals as well as the number of rainfall days (but not heavy rainfall days) for spring over most of the province since 1981. On interannual time scales, the results indicate that dry (wet) springs over the Eastern Cape are associated with a cyclonic (anticyclonic) anomaly southeast of South Africa as part of a shift in the zonal wavenumber 3 pattern in the midlatitudes. Over the landmass, a stronger (weaker) Botswana High is also apparent with increased (decreased) subsidence over and near the Eastern Cape which is less (more) favourable for cloud band development and hence reduced (enhanced) rainfall during dry (wet) springs. Analysis of mid-century (2040-2060) CMIP5 rainfall projections suggests that there may be a flattening of the annual cycle over the Eastern Cape with the winter becoming wetter and the summer drier. For the spring season of interest here, the multi-model projections also indicate drying but less pronounced than that projected for the summer.
\end{abstract}

Keywords Drought/floods · Rainfall variability $\cdot$ Trends $\cdot$ South Africa

\section{Introduction}

South Africa is facing severe pressure with respect to water security due to an increased water demand with increasing population, poor planning and management of water resources, limited investment into water reservoir infrastructure, and recurring droughts over the past decade. Although droughts often happen in South Africa, in recent decades there has been a tendency for more multi-year droughts to occur. For example, summer rainfall time series for various

C. J. C. Reason

chris.reason@uct.ac.za

1 Department of Oceanography, University of Cape Town, Rondebosch, South Africa

2 OUCE, Oxford University, Oxford, U.K parts of South Africa, including the Eastern Cape and adjoining KwaZulu Natal Province show more multi-year droughts during late 1970s to 2017 than during 1950-late 1970s (Fig. 5 of Blamey et al. 2018a). In February 2018, the Western Cape Province was declared a disaster area after a severe drought which occurred between 2015 and 2018 (Pienaar and Boonzaaier 2018; Sousa et al. 2018; Mahlalela et al. 2019; Burls et al. 2019). In October 2019, the Eastern Cape Province (see Fig. 1 for its location in South Africa) was declared a drought disaster region following pronounced water shortages in many urban and rural areas.

The Eastern Cape is of interest not just because of the severe drought that it is currently experiencing but also because its western parts lie near the transition zone between the summer (most of southern Africa) and winter rainfall regions (southwestern South Africa, Reason et al. 2002; Blamey et al. 2018b) and because it is a region of 
Fig. 1 a The mean austral spring and summer (September-February) rainfall (shaded; $\mathrm{mm}$ ) across southern Africa based on CHIRPS data from 1981 to 2018. b A zoomed in version of the mean spring and summer rainfall for the southeast region of the domain. The green polygon in both panels illustrates the location of the Eastern Cape Province in South Africa. Also shown in panel $\mathbf{b}$ are the locations of the South African Weather Service rain-gauges used in the study (a) SONDJF Mean

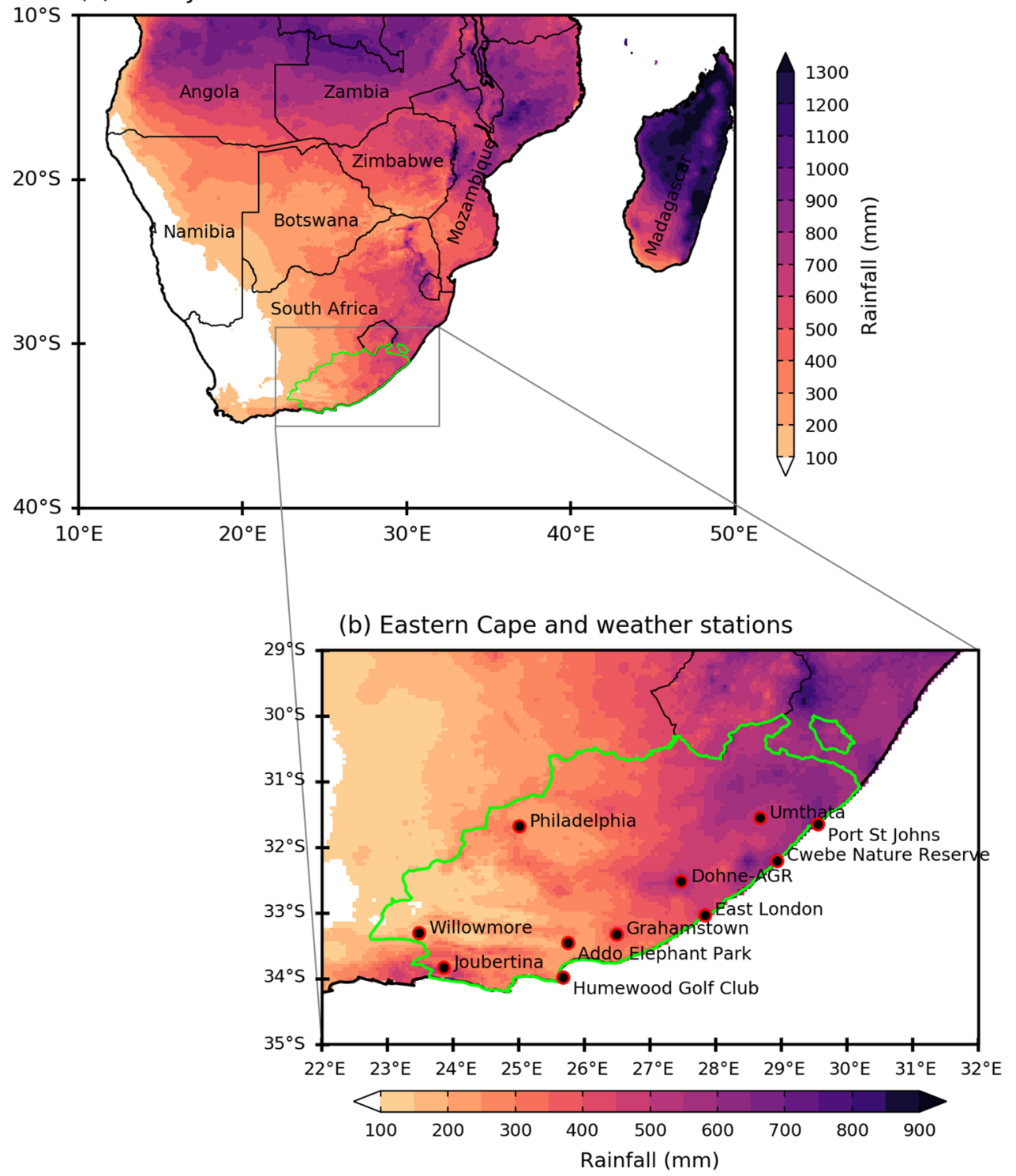

sharp vegetation, soil moisture and topographic gradients (Fig. 2a). As a result, the meteorology here is complex and often involves interactions with the regional topography or the neighbouring warm Agulhas Current (e.g., Rouault et al. 2002; Singleton and Reason 2006). It was argued by Jury et al. (1993) that the distance from the Eastern Cape coast to the core of this current which is of order a few $10 \mathrm{~s}$ of $\mathrm{kms}$ north of $33^{\circ} \mathrm{S}$ but of order $100 \mathrm{~km}$ by the time the current reaches $34^{\circ} \mathrm{S}$, may play a role in the strong decrease in mean rainfall along the Eastern Cape coast (see Fig. 1b). The coast near Port Elizabeth at $34^{\circ} \mathrm{S}$ is relatively dry as is the western interior which forms part of the Karoo semidesert of the central-western inland regions of South Africa. The western coast of the Eastern Cape merges into the small all-season rainfall region that extends along the south coast of South Africa between about $22-25^{\circ} \mathrm{E}$ (Weldon and Reason 2014;
Engelbrecht et al. 2015). From about East London ( $28^{\circ} \mathrm{E}$, $33^{\circ} \mathrm{S}$ ) northwards, the coastal regions are much wetter as are the northeastern inland regions of the Eastern Cape near the Drakensberg and Maluti mountains (Lesotho). Figure 1 shows the rainfall gradients and totals across the Eastern Cape during the spring and summer in relation to those that exist across the rest of southern Africa (summer rainfall dominated everywhere except for western South Africa and the south coast of South Africa).

Precipitation over the Eastern Cape region is influenced by weather systems from both the tropics and midlatitudes, ranging from small-scale convective storms to synoptic-scale tropical-extratropical cloud bands (known locally as tropical-temperate troughs-TTTs). These cloud bands are the major synoptic rainfall producing system over subtropical southern Africa during the early 
(a)

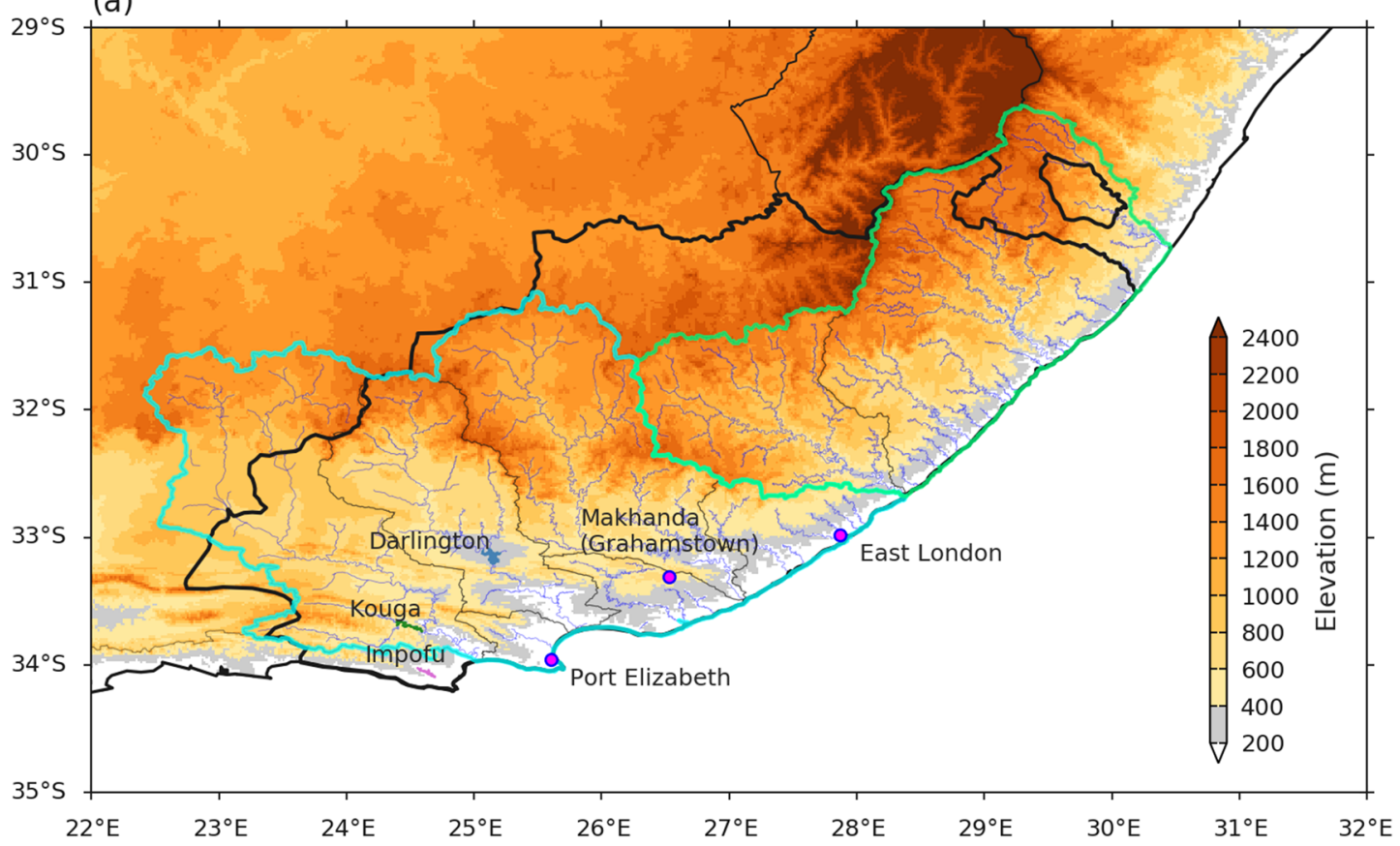

(b)
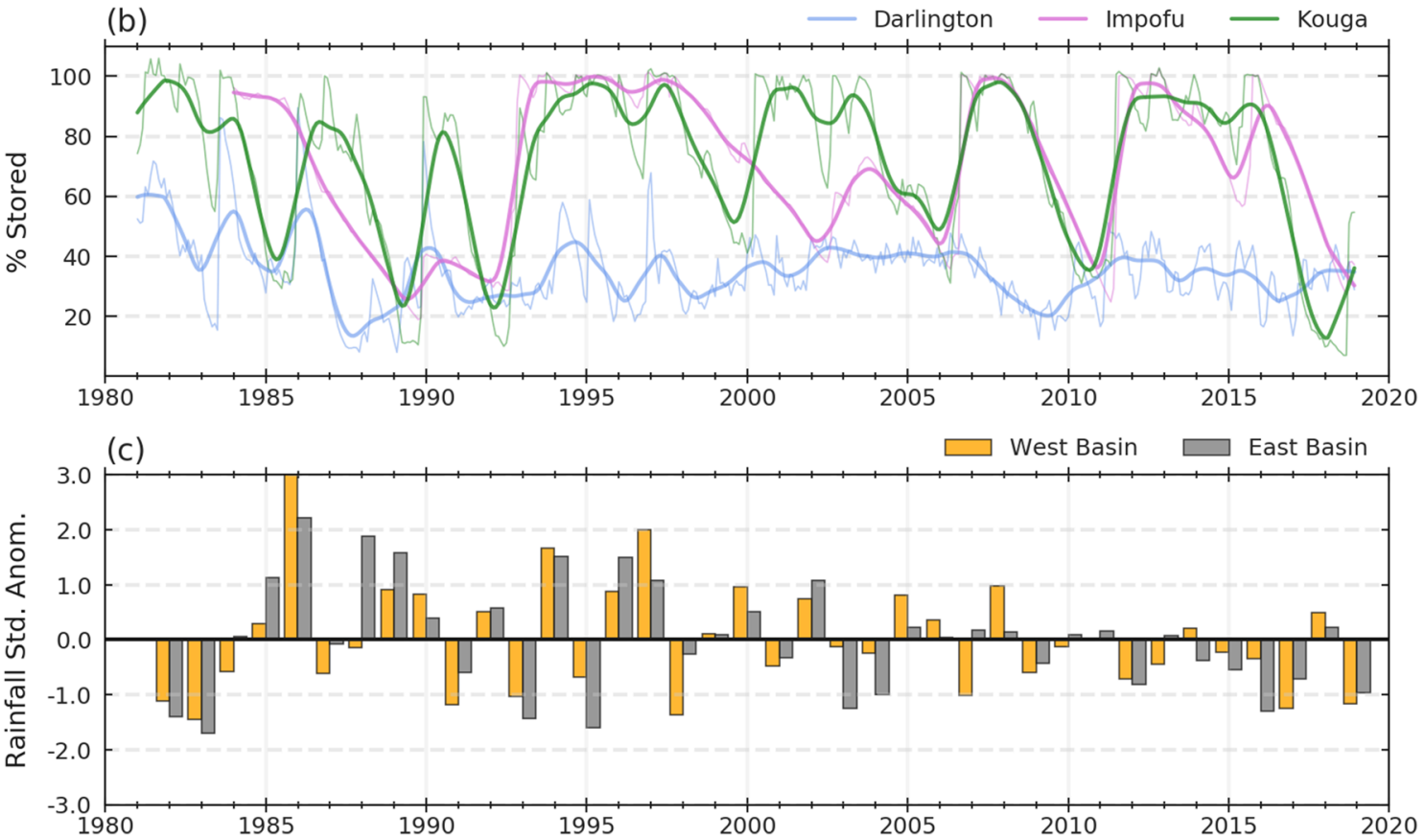

Fig. 2 Panel a illustrates the topography (shaded; $m$ ) of the domain along with the various rivers and river basins. The river basins have been merged into a "west" and "east" basin to highlight some of the regional rainfall differences. Also shown are the locations of the main dams of the region that have seen large water level drops as well as locations of the main towns/cities. Panel b shows the smoothed monthly dam levels (given in \% stored) from around 1981 until 2018, while panel $\mathbf{c}$ shows the austral summer rainfall standardized anomalies, based on CHIRPS, for the regions defined as west and east basin in panel a to mid-summer (Harrison 1984; Diab et al. 1991; Todd and Washington 1999; Hart et al. 2010; Manhique et al. 2011). Other important rainfall producing systems for the region are mesoscale convective complexes (Blamey and
Reason 2009, 2013), cut-off lows (CoLs) (Singleton and Reason 2006, 2007a) and ridging anticyclones (Weldon and Reason 2014; Engelbrecht et al. 2015; Engelbrecht and Landman 2016). 
Also shown in Fig. 2a are the catchment areas of the main dams supplying the province's largest municipality (Nelson Mandela Bay) which contains the major coastal city of Port Elizabeth (located near $34^{\circ} \mathrm{S}$ ) (termed the "west" basin) as well as those for rivers draining the wetter northeastern part of the province (termed the "east" basin). The impact of the current drought can be seen in the levels (Fig. 2b) of two of the larger supply dams (Impofu and Kouga). After being close to full in 2015, both dams have fallen to their lowest levels since 1985 with the decline during 2017-2019 being especially sharp. As of June 2020, the Kouga dam sits at 7\% with the combined supply dam capacity for the Nelson Mandela Bay metro having fallen below $20 \%$. Several other major towns in the province (Grahamstown, Graaff-Reinet, Bedford and Queenstown) have also been experiencing very severe water shortages. The ongoing drought has already cost the province over R120 million for drought relief measures. Due to the increased threat to water security in the Eastern Cape and more broadly, South Africa as whole, understanding the variability and trends in rainfall features that influence water availability over this region is of crucial importance for effective management and planning. Furthermore, relatively little work has been done on the climate of the Eastern Cape region compared to other parts of South Africa despite it being an important agricultural part of the country with a sizeable rural population. The region is also one of the least developed of South Africa's nine provinces with many impoverished rural settlements which are particularly vulnerable to drought and severe weather events. It has also been impacted severely by the COVID-19 crisis with almost $20 \%$ of South Africa's total of 400,000 cases by late July 2020 as compared to having less than $12 \%$ of the national population.

Here, focus is placed on the spring season (September-November SON) which seems to show the strongest and most consistent drought signal since 2015. As discussed below, SON contributes between 25 and $35 \%$ of the annual rainfall over the Eastern Cape on average. Furthermore, given its importance for agriculture (fruit, dairy and angora goats are the main exports), severe drought is highly problematic at this time of year when solar insolation, ground temperatures and potential evapotranspiration are also increasing. Thus, the aims of the study are to investigate the post-2015 drought within the context of previous large anomalies in spring rainfall over the last forty years and any long-term rainfall change and to examine the potential mechanisms associated with spring drought in the region.

\section{Data and methods}

Daily rainfall data over the Eastern Cape were provided by the South African Weather Service (SAWS) for January 1981-December 2018 for comparison against daily gridded data (CHIRPS). Only stations with $90 \%$ data available for the full period were included in the analysis, and for which the station location has stayed more or less the same. The locations of 11 weather stations used in this study are shown in Fig. 1b. Due to the restricted spatial coverage of the available SAWS rain gauges, Climate Hazards Infrared Precipitation with Stations (CHIRPS) daily data were used to consider spatial variability of rainfall variability and trends across the Eastern Cape. CHIRPS is a merge of different products including satellite imagery and station values available at $0.05^{\circ}(5 \mathrm{~km})$ spatial resolution on a quasi-global $\left(50^{\circ} \mathrm{S}-50^{\circ} \mathrm{N}\right)$ grid, for the period 1980 to present (Funk et al. 2015). A correlation analysis was done between CHIRPS and station data to assess confidence in the ability of CHIRPS to represent the region.

Daily rainfall data were converted to seasonal totals with Fig. 3 showing the seasonal rainfall climatology across the Eastern Cape. It is clear that spring (SON) and summer (DJF) contribute most of the annual rainfall on average for the bulk of the province. For the coastal zone, spring and summer each contribute about $30 \%$ of the annual total whereas summer dominates in the northern interior (40-45\%). The autumn accounts for about 20-25\% over most of the province with a small region in the far west reaching $30 \%$ whereas for winter, only in the far south, does rainfall in this season reach $15 \%$ of the annual total on average. Here, focus is placed on SON which seems to show the strongest and most coherent drought signal. However, the extended summer (September-April) is also considered when determining anomalously wet and dry seasons for composite analysis of the interannual variability in the seasonal rainfall totals. These anomalously wet (dry) SON seasons were chosen such that they occur in the same year as the overall (SONDJFMA) summer being wet (dry).

Compositing of fields from the NCEP-DOE II reanalysis data (Kanamitsu et al. 2002), at a spatial resolution of $2.5^{\circ}$, are used to examine the circulation anomalies associated with anomalously dry and wet seasons during the study period. Moisture fluxes were computed from the product of the horizontal wind and the specific humidity at the level of interest. NCEP II reanalyses are also used to plot features of semi-permanent anticyclones in the Indian and Atlantic Oceans. For the purpose of this study, the northern, southern, eastern and western extension of the anticyclones is determined as the outer boundary of the $1020 \mathrm{hPa}$ contour in the mean sea level pressure field (MSLP). This contour level is chosen as it is easily identified as closed contour level around the anticyclones, which is not intersected with the neighbouring land masses in either the early or late summer periods. The latitude and longitude of the centre of the South Indian Ocean High is defined here as the location with the maximum in the MSLP field (after applying a 

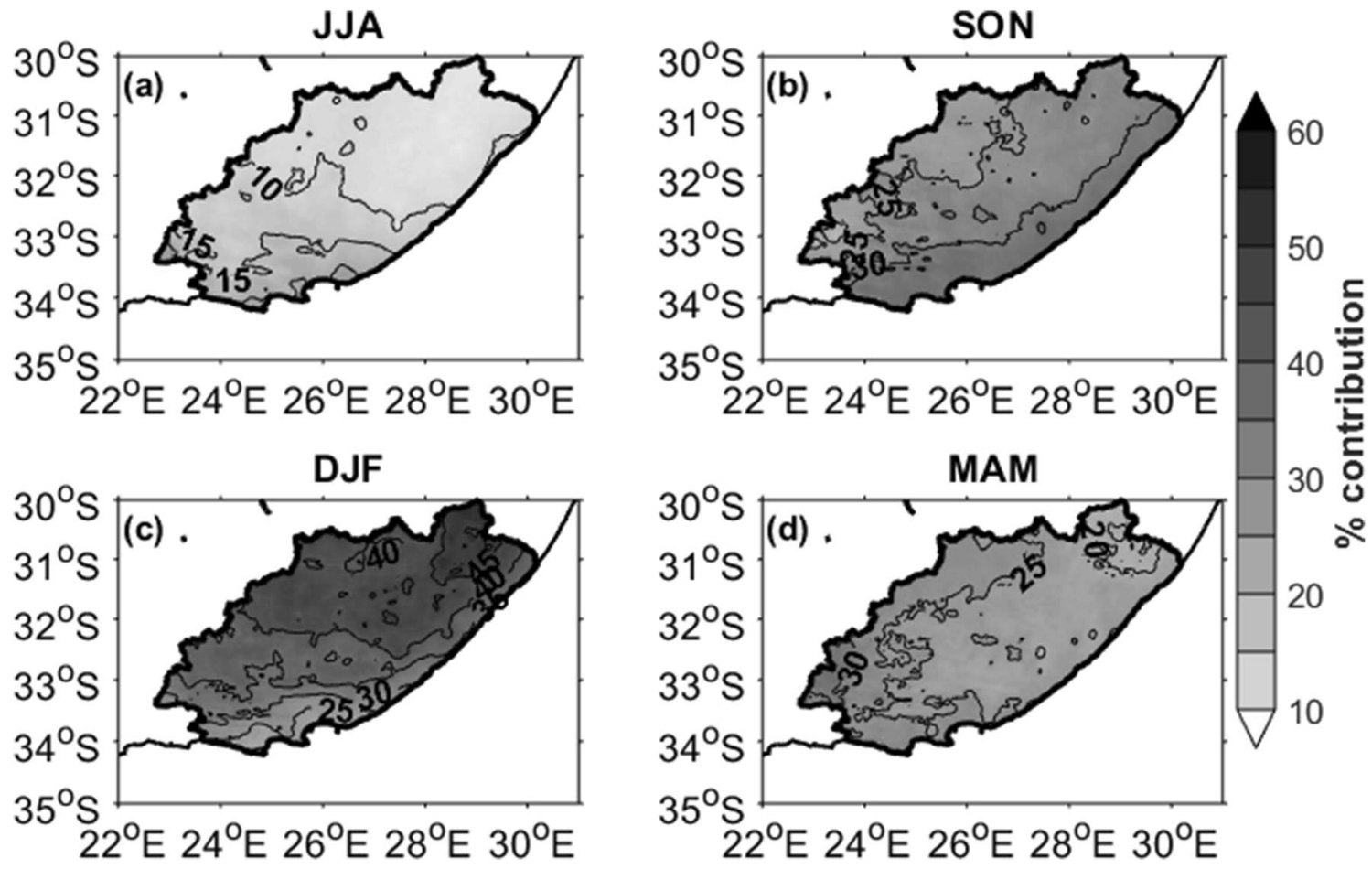

Fig. 3 The mean seasonal rainfall contribution (shaded with contours; in percentage) to the annual rainfall total for a winter-JJA, b springSON, c summer-DJF and d autumn-MAM

spatial smoothing filter) within the climatological mean area $\left(40^{\circ}-110^{\circ} \mathrm{E} ; 15^{\circ}-40^{\circ} \mathrm{S}\right)$.

Trends in various seasonal rainfall characteristics such as the number of rainy days (daily rain $>1 \mathrm{~mm}$ ) and heavy rainfall days (daily rain $>10 \mathrm{~mm}$ ) were evaluated using a non-parametric Mann-Kendall test over the analysis period 1981-2018. This test was used as it makes no assumption about the data distribution and is insensitive to outliers. The magnitude of the trend is calculated using the Sen's slope estimator. This method uses the median of all possible slopes for the given series making it statistically robust. The probability of the trend occurring was measured at a 5\% significance level.

To see whether some insight may be obtained about future rainfall scenarios, a topic of great interest to both the public and the government, future rainfall projections in the region are considered using 36 models from the Coupled Model Intercomparison Project Phase 5 (CMIP5) ensemble (Taylor et al. 2012). A 21 year mid-twenty-first century future period (2040-2060), under the high energy intensive scenario, Representative Concentration Pathway (RCP) 8.5 , was chosen. Only one ensemble member (r1i1p1) per model is included in the analysis. For ease of comparison, precipitation (atmosphere variables) in the models are regridded using bilinear interpolation to a common $1.5^{\circ} \times 1.5^{\circ}$ $\left(2.5^{\circ} \times 2.5^{\circ}\right)$ grid. Rainfall from the models is compared with satellite-based estimates from the Global Precipitation
Climatology Project (GPCP) monthly precipitation data set (Adler et al. 2003) and Climate Prediction Center Merged Analysis of Precipitation (CMAP) (Xie and Arkin 1997).

\section{Spring rainfall variability}

\subsection{Rainfall means and trends}

Figure 4 plots standardized anomalies of SON rainfall for the period 1981-2018 for the 11 available SAWS stations together with CHIRPS data averaged from the 4 grid points surrounding each station (small red boxes in Fig. 1b). Note that the annual cycle from the two datasets is the same for each case (not shown). The time series are correlated at $95 \%$ significance at each station with $r$ values ranging from 0.61 to 0.90 . Note that it is possible that topographic effects or other local forcing may lead to the differences between the time series. Although the sign of the anomalies is almost always the same for each station, there are some springs when there are sizeable differences in magnitude at some stations. However, the correspondence between the two time series during the almost 40 year period at both coastal and inland stations provides sufficient confidence in the ability of the CHIRPS data to adequately represent rainfall variability and change across the province. All of the stations except the two western near-coastal locations (Joubertina 


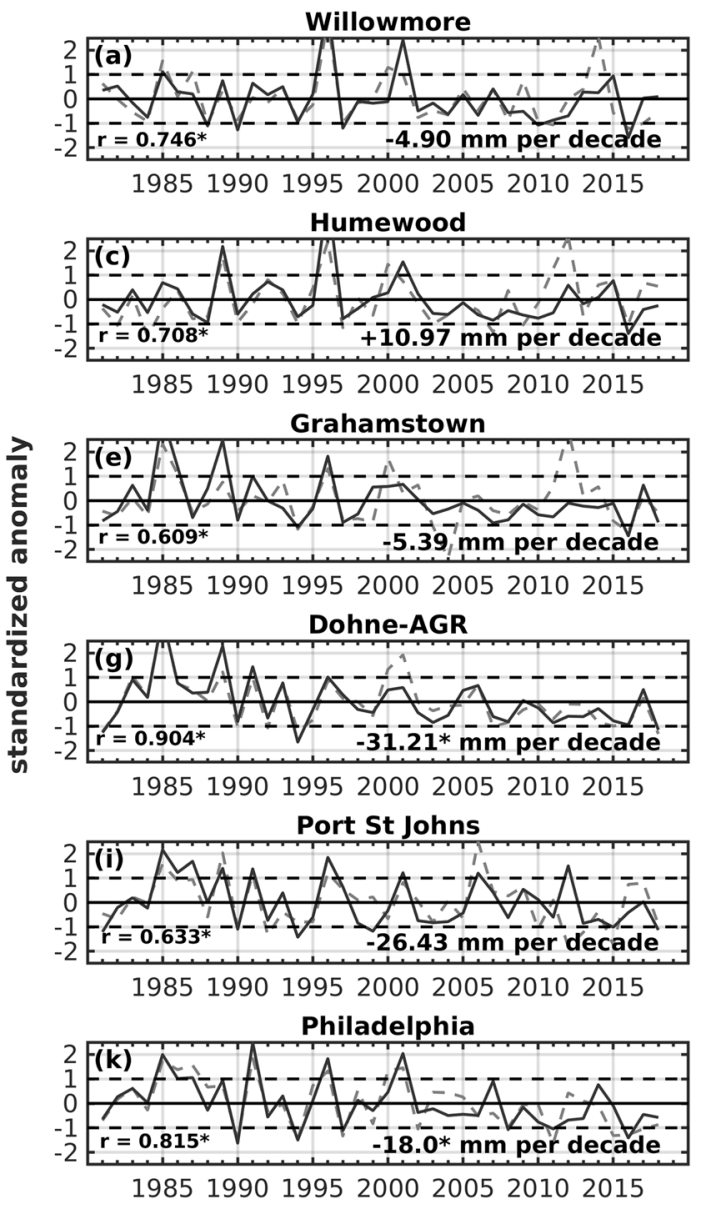

Fig. 4 Spring (SON) standardised anomalies for the eleven stations (grey-dashed line) across Eastern Cape (see Fig. 1b) and the corresponding CHIRPS (black-solid line) anomalies. The station names are indicated at the top of each panel. The correlation between the two datasets is given at the bottom left of each panel. The trend in

and Humewood) show a decreasing tendency in spring rainfall but only the negative trends at Dohne and Philadelphia are statistically significant.

Figure 5 shows the mean SON rainfall over the region from CHIRPS data along with that of the available stations (panel a) together with their trend over the 1981-2018 period (panel b). Most of the region shows a statistically significant decline in spring rainfall, particularly in the east, north and northeast. The weak decrease near Port Elizabeth is not significant but part of the catchment areas in the "west" basin to the north and northwest of this city are. Given that the decrease is much stronger in the wetter eastern half of the province, the results imply that the rainfall gradient across the province (Fig. 5a) is weakening, at least in spring. The stronger decrease in the east is concerning given the larger rural population here and its greater importance for agriculture to the provincial economy (particularly dairy, pineapples and tea).
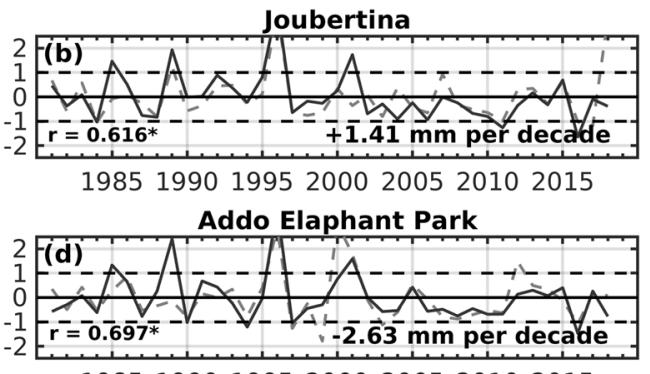

1985199019952000200520102015

East London

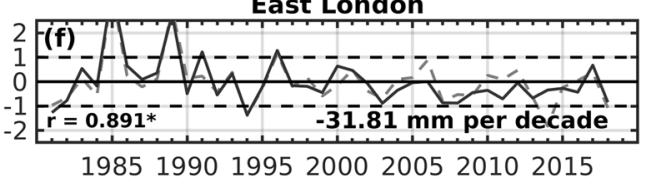

Cwebe Nature Reserve

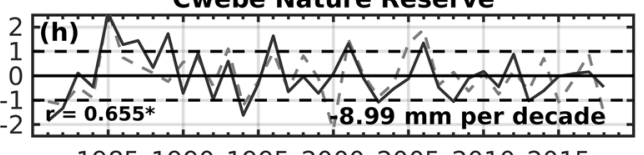

1985199019952000200520102015

Umtata

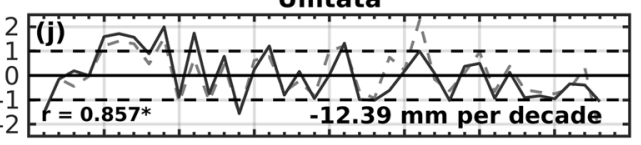

1985199019952000200520102015

SON rainfall for each station is given the bottom right hand corner of the panel (in mm per decade). For both the correlation and the trend analyses, the asterisk denotes significance at the $95 \%$ level using a Student t-test

Maps of the number of rain days ( $>1 \mathrm{~mm}$ per day), heavy rain days ( $>10 \mathrm{~mm}$ per day) and their trend across the province are plotted in Fig. 6 using CHIRPS data. A contrast exists between fewer (more) rain days in the west/ southwest (northeast) consistent with rainfall totals being of order $50-150 \mathrm{~mm}$ in the former and $250-400 \mathrm{~mm}$ in the latter region (Figs. 5a, 6a). There is less of a contrast in the distribution of heavy rainfall days across the province with only the north coast showing a much greater frequency than the south (Fig. 6c). In terms of trends (Fig. 6b, d), the strongest negative trends are again in the north and northeast with that in rain days making a more obvious contribution to the rainfall total decreasing trends (Fig. 5b) than that in heavy rain days. In the far west, it is notable that the area of significant decrease in both rain and heavy rain days represents part of the Kouga and Impofu dam catchment areas in the "west" basin that feed into the Port Elizabeth urban area. 

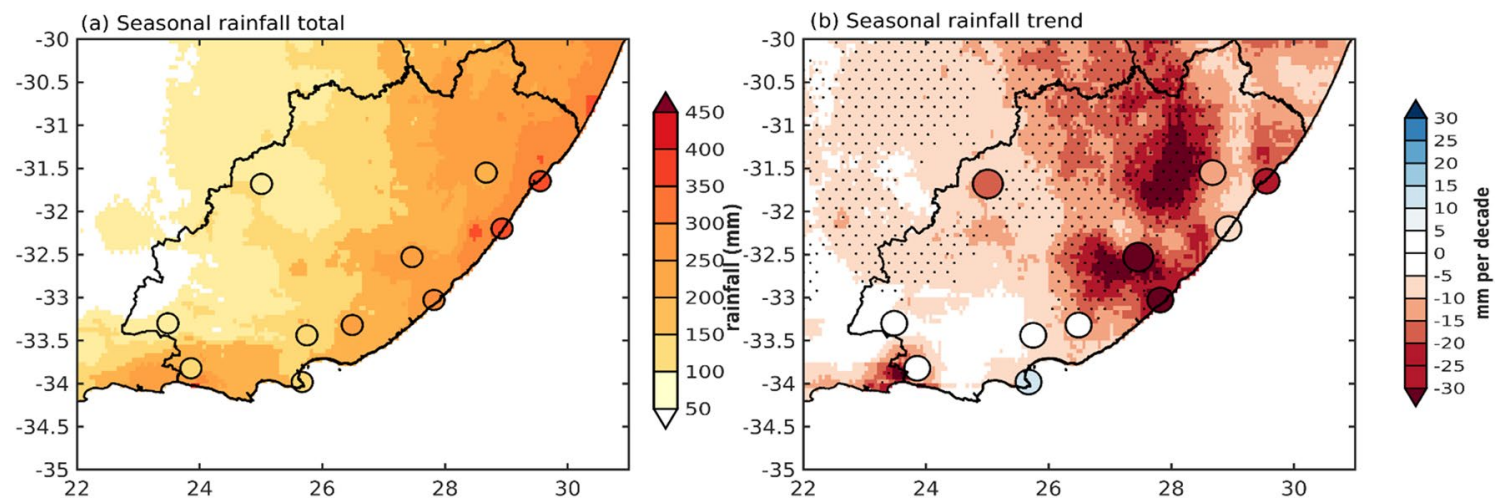

Fig. 5 a The mean SON rainfall in CHIRPS (shaded; mm) and SAWS stations (circles; $\mathrm{mm}$ ) and $\mathbf{b}$ the corresponding trend in SON rainfall over the period 1981-2018. Stippling or larger circles denotes values significant at a 95\% level using a two-tailed Mann-Kendall test

(a) Seasonal rainfall days total

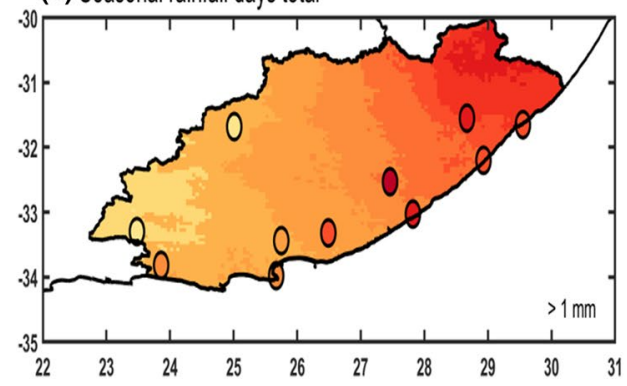

(c)

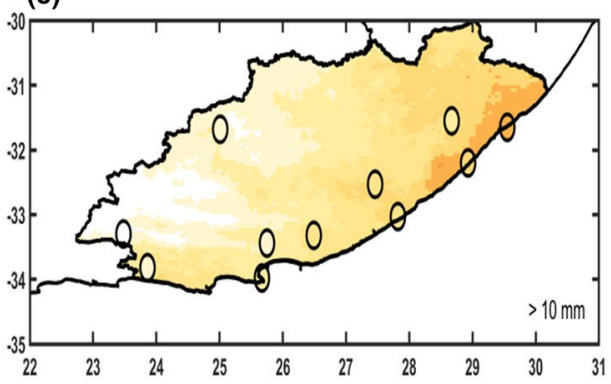

Fig. 6 a The climatological number of rain days in SON (daily rain $\geq 1 \mathrm{~mm}$ ) over the Eastern Cape Province and $\mathbf{b}$ the trend in the SON rain days (given as days per decade) in CHIRPS data and SAWS

In terms of the recent period, all stations (Fig. 4) show average to well below average rainfall during SON 2015 with several also showing that a sharp decline occurred in this season with little or no recovery during 2016-2018. Only Willowmore appears to show average rainfall by SON 2018 whereas the partial recovery at the other two westernmost stations (Humewood and Joubertina) in 2017 is then followed by more negative rainfall anomalies in 2018 . Examination of GPCC data (not shown) indicates that most of South Africa including the entire Eastern Cape received below average rainfall in SON 2019. Although a run of several years of below average rainfall is not uncommon in (b) Seasonal rainfall days trend

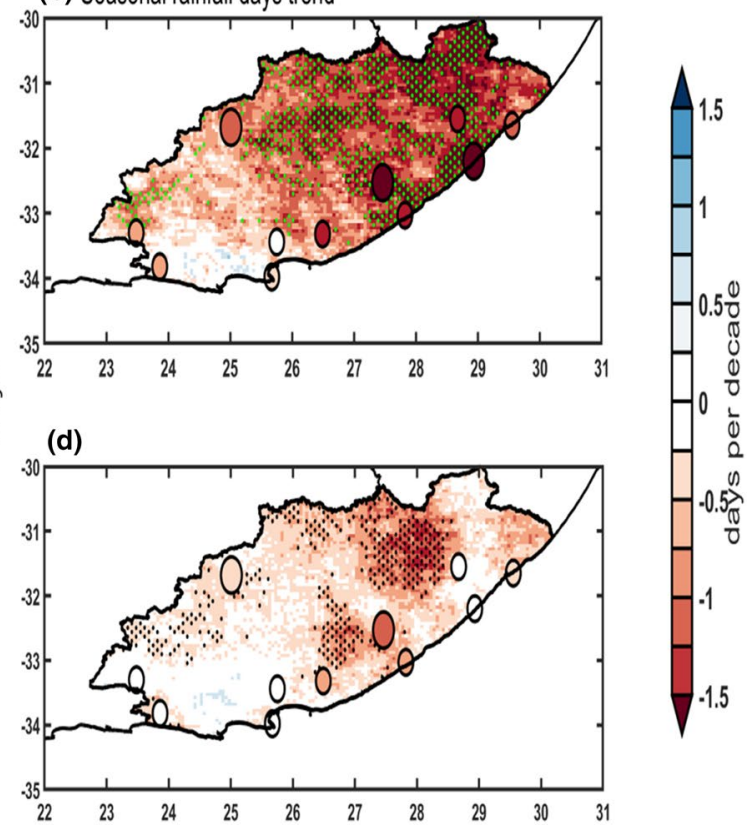

stations (circles) over the period 1981-2018. c, d, same as a, b but for rain days $\geq 10 \mathrm{~mm}$. Stippling (green or black) or larger circles denotes values significant at a $95 \%$ level using a two-tailed Mann-Kendall test

spring (Fig. 4), or indeed in summer (Blamey et al. 2018a), in the Eastern Cape, it is clear that most of the consecutive years of dry springs have occurred in the most recent decade whereas most of the well above average rainfall springs occurred between 1981-2005. This run of recent consecutive dry springs is consistent with the trend results (Figs. 5, 6) and implies that the sharp decline at most stations since 2015, with little recovery in rainfall since, has led to the recent drought having more devastating impacts than would otherwise be the case due to depletion of surface and groundwater resources over a long period. Furthermore, spatial maps (not shown) of CHIRPS rainfall anomalies 
across the region for spring show that the last significantly wet season (spatially averaged standardised anomaly of 1.35) occurred in 2001 with only three of the springs between 2003 and 2018 showing positive anomalies (0.18 in 2006, 0.26 in 2007 and 0.09 in 2014). The remaining springs are all dry to very dry except for $2005(-0.01)$ with the recent springs of 2016 and 2018 showing anomalies of -1.11 and -0.84 , respectively.

Based on springs that were followed by summers of the same signed anomaly, then the following seasons were respectively defined as significantly dry (1981, 1990, 1994, 2008, 2016) or wet $(1985,1989,1993,1996$, 2001) (Table 1). Even with this stricter criterion of the extended summer "half" of the year (September-April) being anomalously dry or wet, it is evident that all of the latter occurred in the first two decades of the period. The dry seasons are more evenly spread out although 2 of the 5 occurred in the last decade. However, if the criterion about the subsequent summer is relaxed, then the wet springs remain the same but the dry seasons are slightly changed $(1990,1994,2011,2016,2018)$ with now 3 of the 5 in the last decade. To examine potential mechanisms associated with these anomalous seasons, the next section considers composites of various circulation fields.

\subsection{Interannual variability: potential mechanisms}

To assess potential mechanisms associated with the interannual rainfall anomalies, composites of $500 \mathrm{hPa}$ geopotential height and omega, $850 \mathrm{hPa}$ moisture flux and divergence, and OLR are analysed for the spring seasons in Table 1. Figure 7 shows that dry (wet) springs over the Eastern Cape are associated with a cyclonic (anticyclonic) anomaly to the southeast of South Africa which is part of a wavenumber 3 or 4 pattern in the Southern Hemisphere midlatitudes. Further north over Namibia, Botswana and Angola there are positive (negative) anomalies implying a stronger (weaker) mid-level Botswana High which has been previously associated with drier (wetter) conditions over subtropical southern Africa in late summer (Reason 2016; Driver and Reason 2017). The cyclonic (anticyclonic) anomaly southeast of South Africa is also evident at lower levels leading to an enhancement (reduction) in offshore dry flow (Fig. 8b, c) relative to the $850 \mathrm{hPa}$ climatological moisture flux (Fig. 8a) in the dry

Table 1 Spring (September-November) seasons used for the composites

\begin{tabular}{ll}
\hline Dry & $1981,1990,1994,2008,2016$ \\
Wet & $1985,1989,1993,1996,2001$
\end{tabular}

These 5 driest (wettest) seasons during 1981-2018 are chosen based on the extended summer (September-November plus the following December-April) being anomalously dry or wet

\section{(a) Dry SON composite}

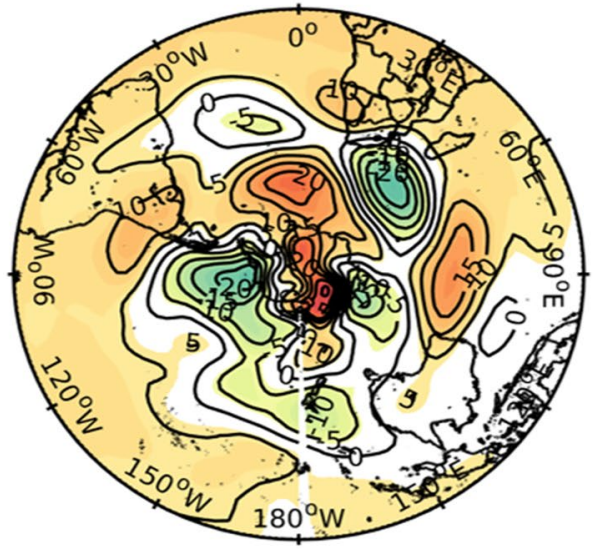

(b) Wet SON composite

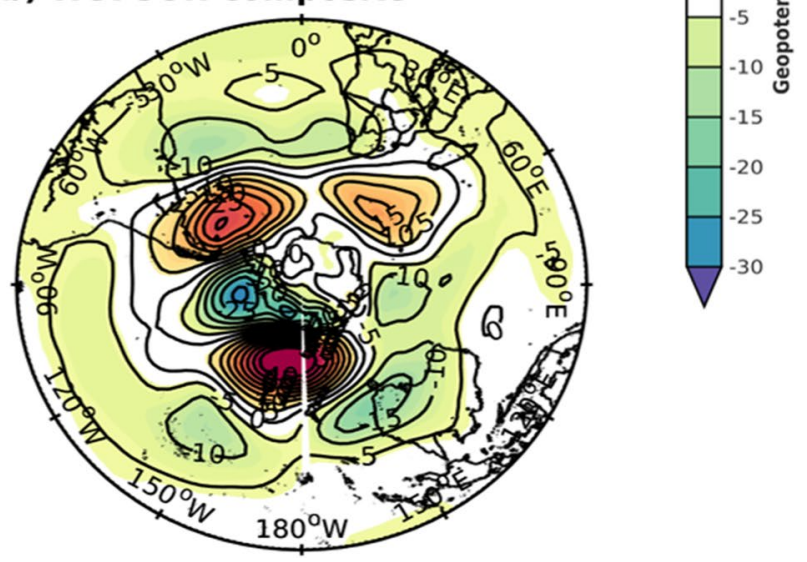

Fig. 7 SON geopotential height composite anomaly (shaded with contours; m) at the $500 \mathrm{hPa}$ level for a dry and b wet springs

(wet) springs. There is relative divergence (convergence) of this low-level moisture over the neighbouring Agulhas Current unfavourable for the strengthening (weakening) of rain-producing weather systems in the region such as ridging anticyclones, cold fronts and cloud bands. SST composites (not shown) indicate cool (warm) anomalies in the greater Agulhas Current region which have previously been associated with dry (wet) summers over eastern South Africa (e.g., Walker 1990; Mason 1995; Reason and Mulenga 1999; Reason 1999). The omega anomalies (Fig. 9a, b) support this suggestion of changes in the strength of weather systems over the Eastern Cape with strong relative subsidence (uplift) over most of the Eastern Cape as well as much of South Africa and the ocean to the south of the country in the dry (wet) composite. The northwest-southeast orientation of the omega anomalies across western southern Africa suggests unfavourable (favourable) conditions for cloud band development during the dry (wet) springs. Using the met-bot 
Fig. 8 a The mean moisture flux divergence (shaded; $\left.\mathrm{g} \mathrm{kg}^{-1} \mathrm{~s}^{-1} \times 10^{-5}\right)$ and moisture flux (scale vector shown) during SON at the $850 \mathrm{hPa}$ level. Panels b, $\mathbf{c}$ show the composite anomalies for dry and wet springs respectively (shaded; $\mathrm{g} \mathrm{kg}^{-1} \mathrm{~s}^{-1} \times 10^{-6}$ )

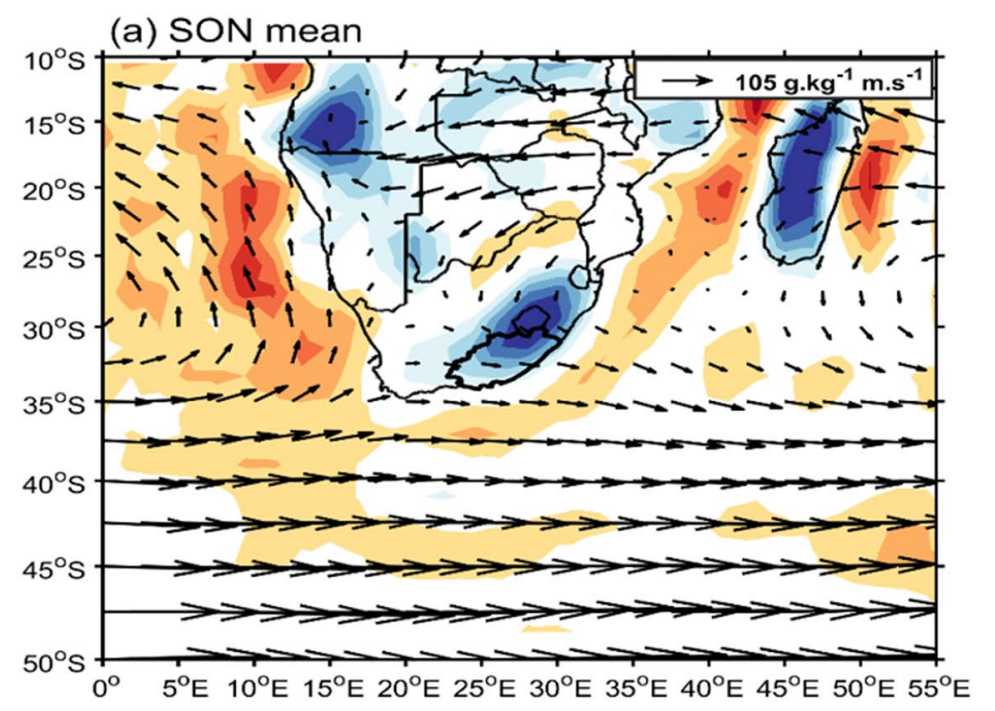

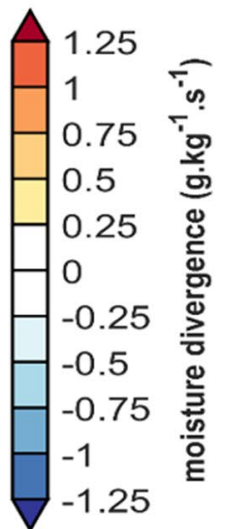

(b) SON dry composite

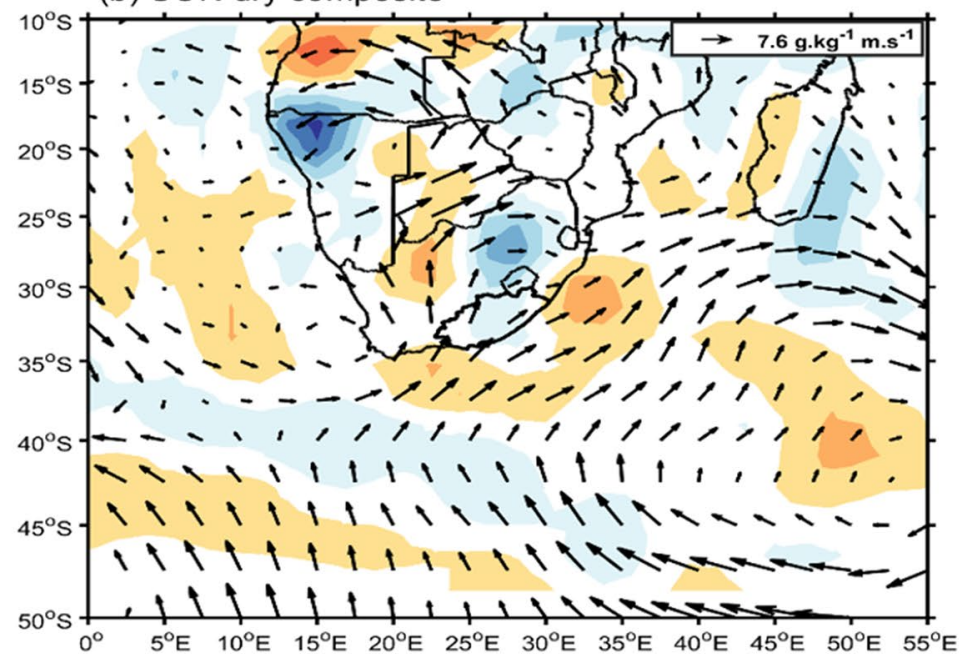

(c) SON wet composite

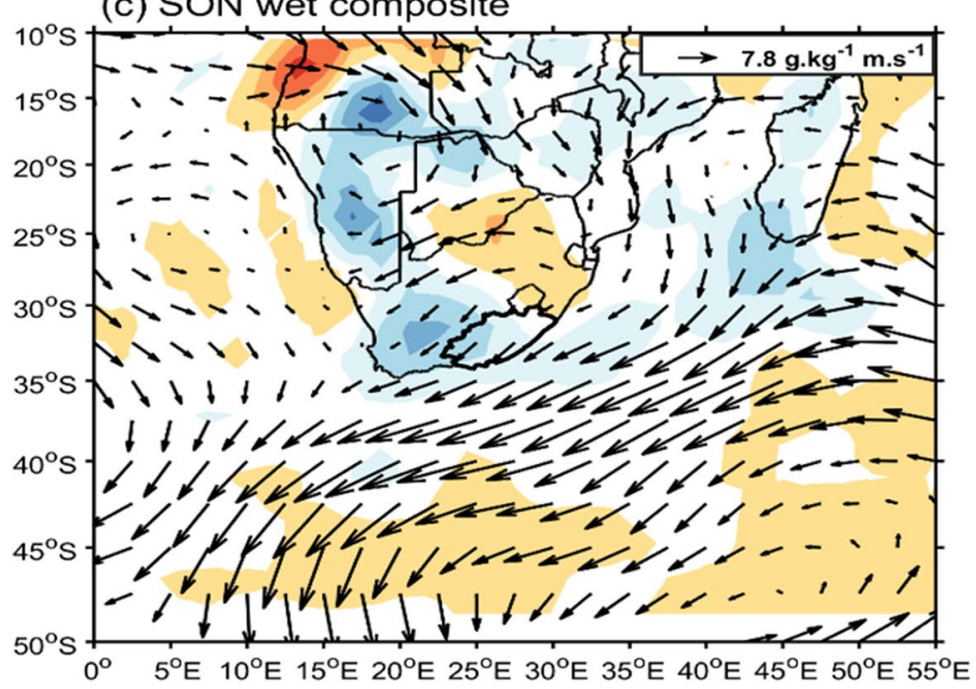

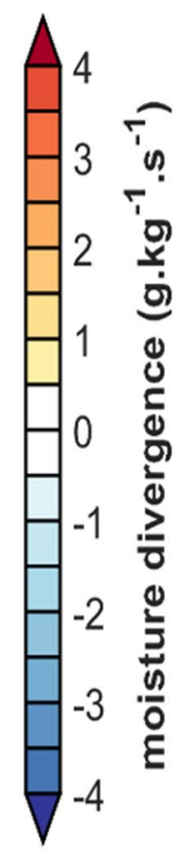


Fig. 9 SON composite anomaly of omega (shaded with contours; $\mathrm{Pa} \mathrm{s}^{-1}$ ) at the $500 \mathrm{hPa}$ level for $\mathbf{a}$ dry and $\mathbf{b}$ wet springs
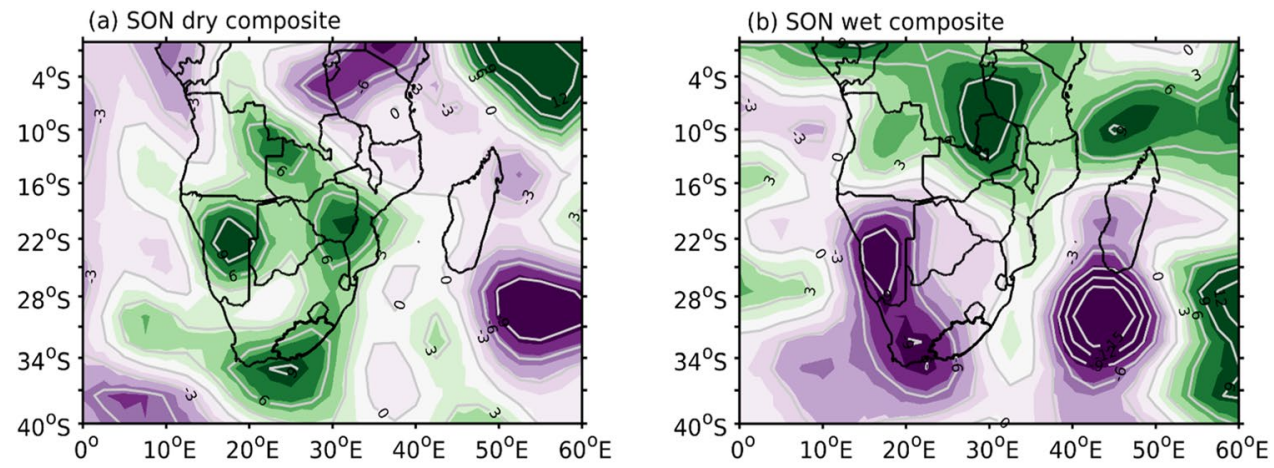

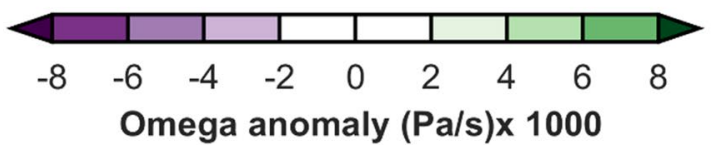

cloud band tracking methodology developed by Hart et al (2012), it is found that there are indeed about 1-2 less (more) cloud band days than average during the dry (wet) springs over much of South Africa, including most of the Eastern Cape. Also evident in Fig. 8b, c is a weakening (strengthening) of the Angola Low and relative offshore (onshore) moisture flow from the tropical South East Atlantic. A stronger Angola Low and this moisture inflow have been found to be important for both synoptic and seasonal scale wet spells in summer over South Africa and the reverse during dry conditions (Mulenga et al. 2003; Cook et al. 2004) since it often acts as the source region for cloud bands. Figure 10 shows the corresponding OLR composite anomalies again revealing a northwest-southeast orientation which is consistent with less (more) cloud bands/other convective systems and hence decreased (increased) rainfall over the Eastern Cape during the dry (wet) spring seasons.

It is unclear as to whether these circulation patterns for the anomalous springs are related to any of the largescale climate modes that are known to directly affect rainfall over subtropical southern Africa. Indeed none of the hemispheric circulation anomalies in Fig. 7 are obviously reminiscent of these climate modes which are ENSO, the South Indian Ocean subtropical dipole (SIOD), the Benguela Niño, and the Southern Annular Mode (SAM). All of these have strong seasonality to their impacts on regional rainfall over subtropical southern Africa with the first two being important in mid-late summer (December-March) (Lindesay 1988; Mason 1995; Reason et al. 2000; Behera and Yamagata 2001; Reason 2001), the third in the late

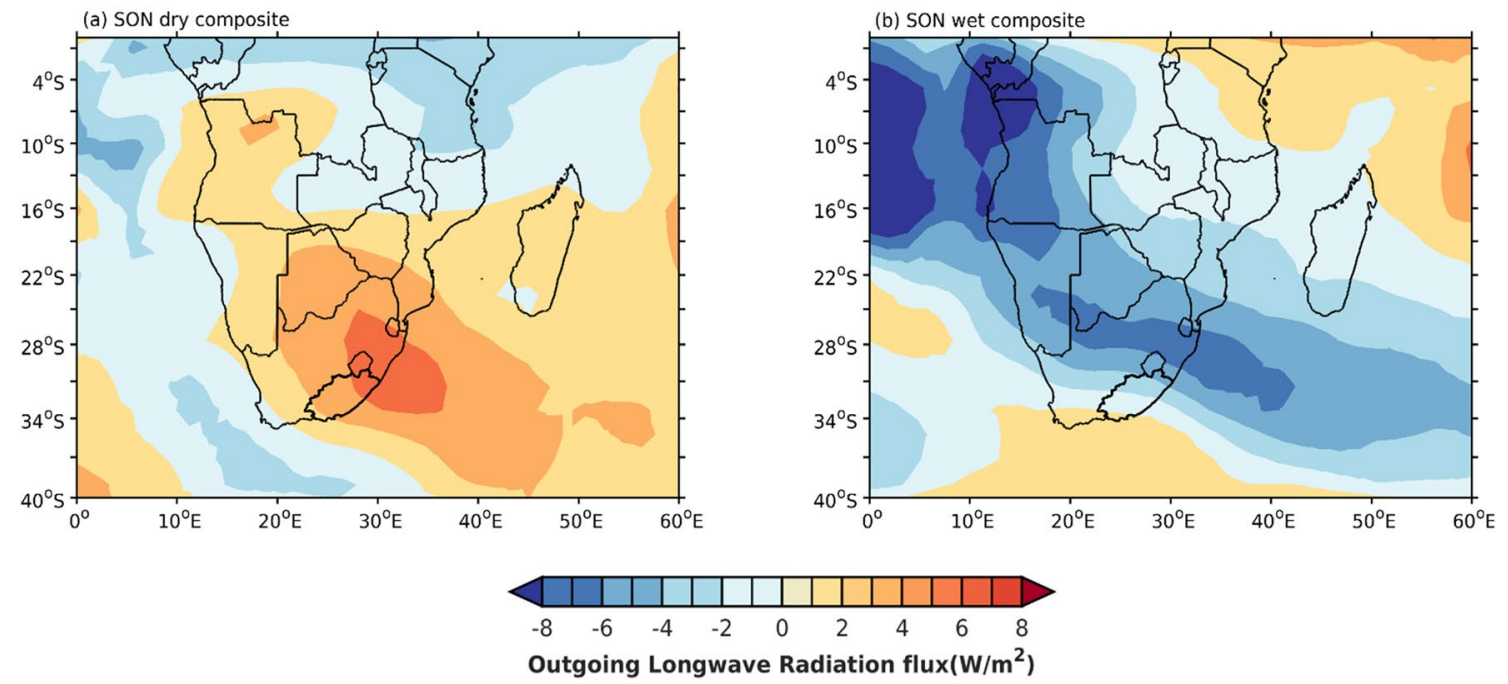

Fig. 10 Composite anomaly of OLR (shaded; $\mathrm{W} / \mathrm{m}^{-2}$ ) for $\mathbf{a}$ wet and $\mathbf{b}$ dry springs 
summer and typically more over Namibia and Angola than South Africa (Rouault et al. 2003; Hansingo and Reason 2009) while SAM impacts have been found in summer (Gillett et al. 2006) over much of the region and over western South Africa in winter (Reason and Rouault 2005). Indeed, correlations of Niño 3.4, the Benguela Niño, the SIOD index (Behera and Yamagata 2001) or the SAM index (Marshall 2003) do not show any significant or coherent signal over the Eastern Cape in spring. Correlations of the spring Eastern Cape rainfall with the Indian Ocean Dipole (DMI) (Saji et al. 1999) which manifests in spring (and is strongly correlated with equatorial East African rainfall) show a negative correlation over the Eastern Cape but it is not statistically significant. For summer, only the SAM index shows a coherent and statistically significant correlation (positive in sense) over the Eastern Cape region (not shown). This lack of consistency of climate signals in not just spring but also in summer (except for SAM) further adds to the challenge of trying to understand the climate variability of this complex region. Because the Eastern Cape includes the transition zone between the winter and summer rainfall dominated regions of South Africa, even small changes in the ways that individual ENSO, SIOD, IOD or SAM events influence the tracks or strengths of rain-producing weather systems crossing the region can have substantial impacts on seasonal rainfall and may preclude any consistent signal.

Although there does not appear to any obvious linkage between these large-scale climate modes and spring rainfall over the Eastern Cape, the wavenumber 3 or 4 patterns in Fig. 7 suggest that changes in the South Atlantic or South Indian Ocean semi-permanent anticyclones might be important. On average during spring, the former anticyclone tends to move southeastward towards southwestern South Africa, signalling the end of the winter rainy season there. The South Indian Ocean High (SIHP) also tends to retreat southeastwards in spring and the continental high over southern Africa breaks down then, coincident with the end of the dry winter half of the year for southern Africa (except the far southwest). On examining the spatial extent and centre of these anticyclones for the composite seasons, it is found that the South Atlantic anticyclone tends to be located further to the southeast (and closer to western South Africa) in drier than wetter springs while the SIHP tends to located nearer Western Australia (eastern South Africa) in the dry (wet) case. These anomalous locations of the anticyclones further encourage less (more) cloud bands and cold fronts over the Eastern Cape region during dry (wet) springs.

For the SIHP, its eastern extent (Fig. 11a) is strongly negatively correlated with SON rainfall over the "west" basin of the Eastern Cape as well as most of western South Africa. The "west" basin also shows a significant negative correlation with the northern extent of the SIHP (Fig. 11d). Based on the climatological moisture flux shown in Fig. 8a, this negative correlation might be related to a more northward extending SIHP leading to a reduced easterly moisture flux into northern South Africa, Zimbabwe and Mozambique and subsequent weaker northerly moisture inflow towards the Eastern Cape and thus drier conditions. It is not obvious that a more eastward extending SIHP could also lead to a negative correlation with rainfall but a possibility is that this location of the SIHP tends to favour cloud bands being located more over the South West Indian Ocean rather than over the landmass (Fauchereau et al. 2009; Hart et al. 2018). The southern and western extents of the SIHP (Fig. 11b, c) are also mainly negatively correlated with Eastern Cape SON rainfall but this is only statistically significant for small areas in the far northeast near Lesotho.

Although Fig. 7 indicated shifts in wavenumber 3 pattern, it can be seen that only the circulation anomaly in the midlatitude South Indian Ocean is consistent between the dry and wet spring composites since the anomalies in the midlatitude South Pacific and South Atlantic are not exactly in the same place. Nevertheless, using a zonal wavenumber 3 index such as that proposed by Raphael (2004) leads to a fairly strong and statistically significant correlation (Fig. 12a) with spring rainfall over much of the Eastern Cape as well as part of the northeast of South Africa. If an index for only the South Indian Ocean component of the wavenumber 3 index is used (standardised anomalies in $500 \mathrm{hPa}$ geopotential height spatially averaged over $45-50^{\circ} \mathrm{S}, 45-60^{\circ} \mathrm{E}$ ) then Fig. $12 \mathrm{~b}$ indicates a statistically significant correlation over the central third of the Eastern Cape (with stronger $r$ values than for the full index) as well as some other parts of subtropical southern Africa in a NW-SE cloud band type orientation.

\subsection{Model rainfall projections}

Given the trends in spring rainfall and rain days (Figs. 4, 5, 6) over the Eastern Cape and the great concern of the public and government about climate change, it is of interest to examine CMIP5 model projections for future rainfall over the region, particularly since there is a likelihood of more extreme rainfall events occurring over southern Africa in the future (IPCC 2013). As already seen in Fig. 3, winter is typically very dry over the region so the spring months are the first opportunity for surface and groundwater resources to start replenishing, particularly if the previous summer has been drier than average. Thus, it is of concern to know whether climate models are projecting that these spring months might become drier in future and how well the models can represent the annual cycle in rainfall.

Figure 13a plots the annual cycle of rainfall over the Eastern Cape for 36 CMIP5 models and for two observed gridded rainfall products that have similar resolution to the models (GPCP and CMAP). The latter show a weak bimodal cycle with November and February as the wettest months; 

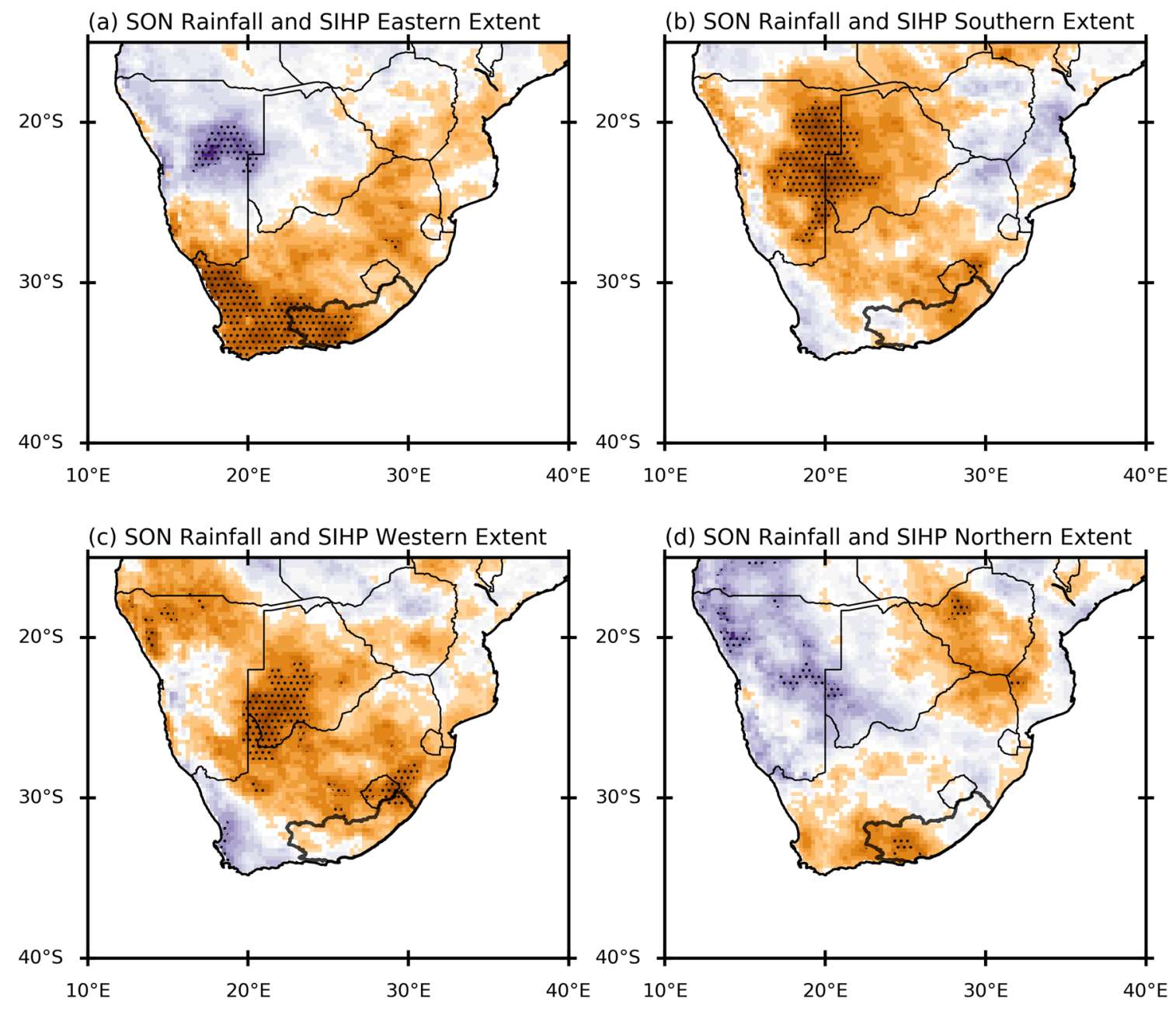

(d) SON Rainfall and SIHP Northern Extent
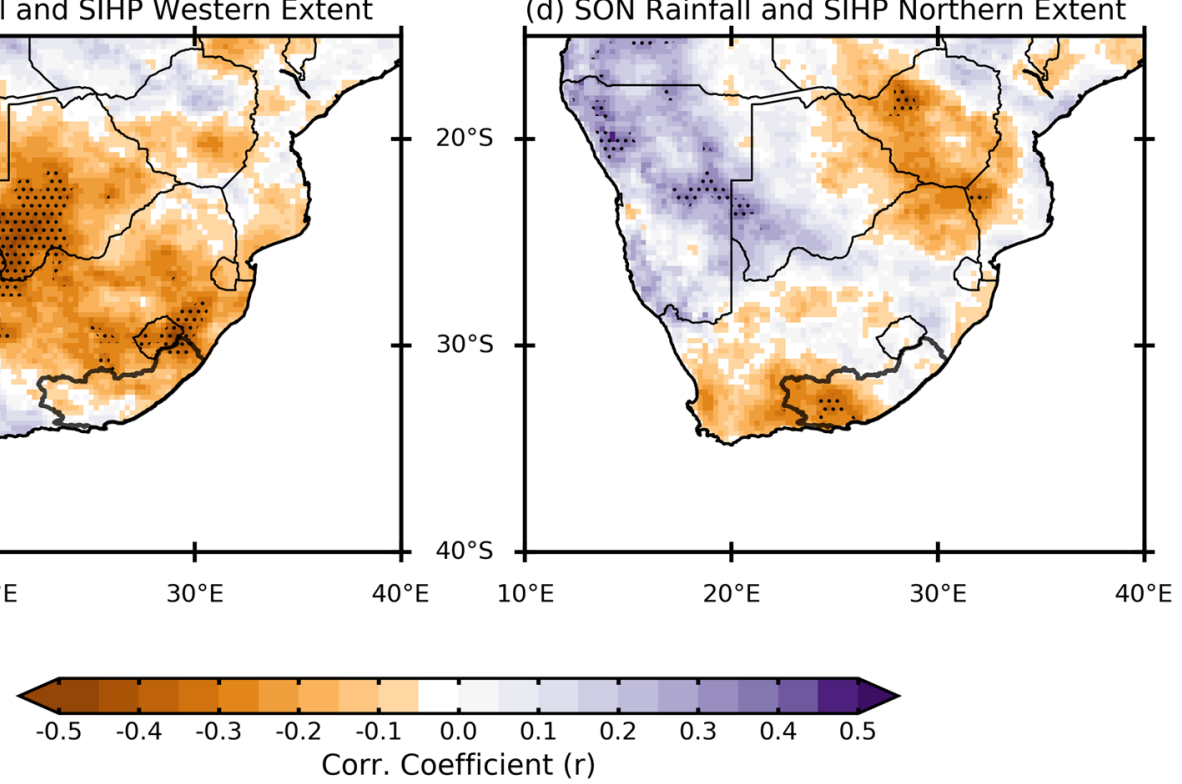

Fig. 11 The correlation between SON rainfall and a eastern, $\mathbf{b}$ southern, $\mathbf{c}$ western and $\mathbf{d}$ northern extent of the South Indian Ocean High Pressure (see text for details). Areas that are statistically significant

however, the bimodal aspects in the dry season are not obvious since May, June and July are all very similar and then the average rainfall starts increasing from August. This bimodal cycle is a weaker version of that evident in Southern Hemisphere regions (and related to the semiannual oscillation) which are located more in the mid-latitudes such as southern Victoria, Australia which extends to $38^{\circ} \mathrm{S}$ as compared to the Eastern Cape which lies north of $33-34^{\circ} \mathrm{S}$. Almost all the models show a much wetter summer half of the year than winter but only some show February or November as the wettest months. In general, most of the models are too wet so that the multi-model mean (black dashed line), although showing February as the wettest month (but no secondary peak in November), indicates up to $2 \mathrm{~mm}_{\text {day }}{ }^{-1}$ more rainfall at the $95 \%$ level are denoted by stippling. The location of the Eastern Cape river basins is denoted with the black polygon

than CMAP or GPCP on average. However during spring, the wet bias is smaller $\left(1 \mathrm{~mm} \mathrm{day}^{-1}\right)$ with November being the wettest month as observed; the lack of a small decrease from November to December in the multi-model mean unlike in the observed is not directly relevant to the spring focus in this study.

Figure 13b, c plot the mid-century (2040-2060) projections in the annual cycle under the RCP8.5 scenario for each model and the multi-model mean together with the difference from the current climate. These figures indicate that the models are projecting a slight flattening of the annual cycle with the winter becoming wetter and the summer drier. For the spring season of interest here, the multi-model projections also indicate a drying but less pronounced than for 


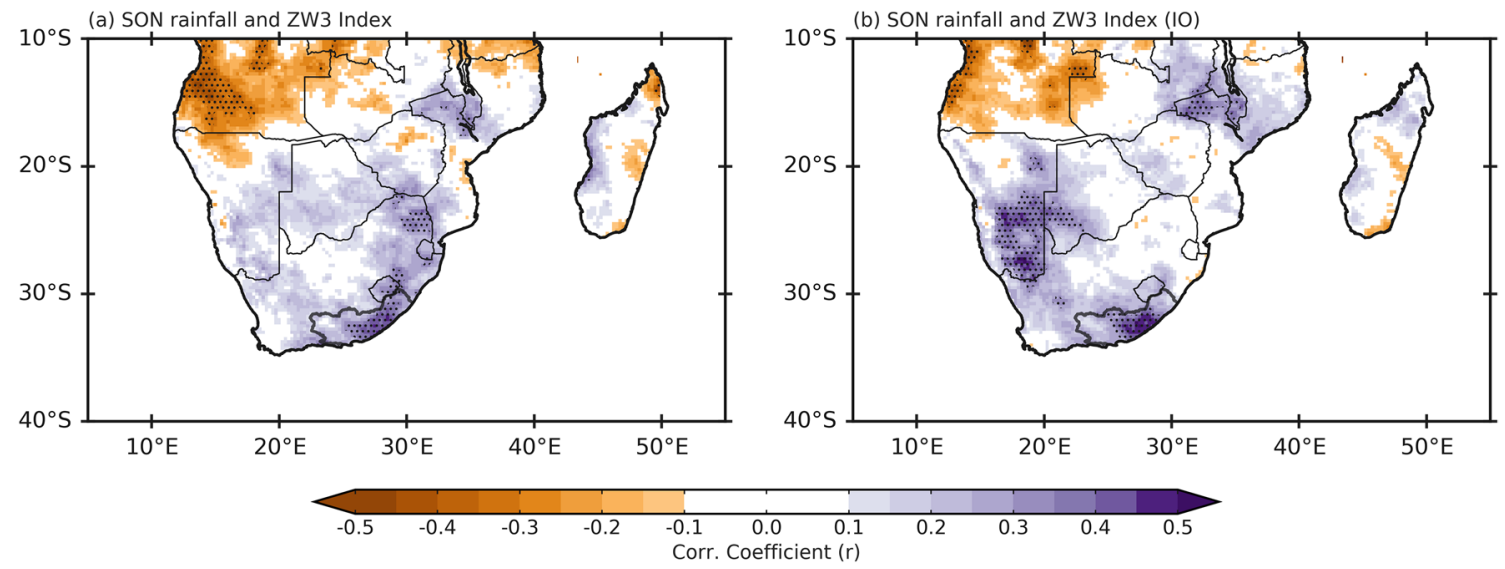

Fig. 12 The correlation between SON rainfall and a the zonal wave number 3 index of Raphael (2004) and b only the South Indian Ocean High component of that index. Areas that are statistically significant at the $95 \%$ level are denoted by stippling. The location of the Eastern Cape river basins is denoted with the black polygon
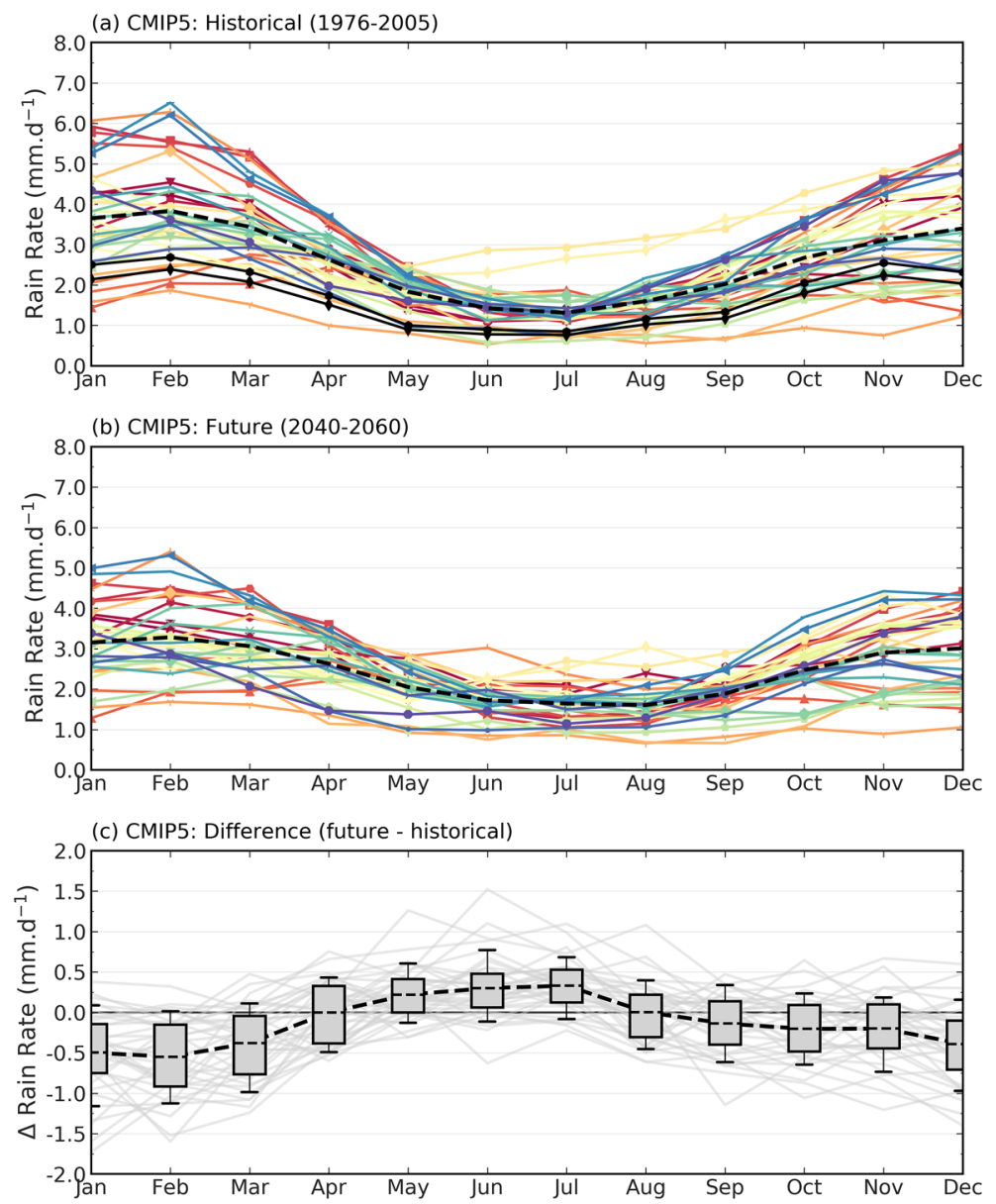

\begin{tabular}{|c|c|c|c|}
\hline$\rightarrow-$ & ACCESS1-0 & & HadGEM2-CC \\
\hline$\rightarrow$ & ACCESS1.3 & - & HadGEM2-ES \\
\hline$\rightarrow$ & BNU-ESM & $\rightarrow-$ & IPSL-CM5A-LR \\
\hline - & CCSM4 & $\leadsto$ & IPSL-CM5A-MR \\
\hline$\rightarrow$ & CESM1-BGC & $\simeq$ & IPSL-CM5B-LR \\
\hline$\rightarrow-$ & CESM1-CAM5 & $\rightarrow-$ & MIROC-ESM-CHEM \\
\hline$\rightarrow$ & CMCC-CESM & $\leadsto-$ & MIROC-ESM \\
\hline & CMCC-CM & $\longrightarrow$ & MIROC5 \\
\hline+ & CMCC-CMS & $\rightarrow$ & MPI-ESM-LR \\
\hline & CNRM-CM5 & - & MPI-ESM-MR \\
\hline يم & CSIRO-MK3-6-0 & - & MRI-CGCM3 \\
\hline & CanESM2 & - & NorESM1-M \\
\hline$\rightarrow-$ & EC-EARTH & $\leftarrow$ & NorESM1-ME \\
\hline & FGOALS_g2 & $\rightarrow$ & bcc-csml-1-m \\
\hline$y^{2}$ & FIO-ESM & $\longrightarrow$ & bcc-csm1-1 \\
\hline$\Leftrightarrow$ & GISS-E2-H-CC & $\rightarrow$ & inmem4 \\
\hline & GISS-E2-H & -- & MMM \\
\hline & GISS-E2-R-CC & $\rightarrow$ & CMAP \\
\hline & GISS-E2-R & $\rightarrow$ & GPCP \\
\hline & HadGEM2-AO & & \\
\hline
\end{tabular}

For comparison, two observation products (CMAP and GPCP) are included in a (black solid lines). The multi-model mean (MMM) is represented by a black dashed line in all three panels. Box plots in $\mathbf{c}$ cover the 10th-90th percentile range of a change in rain rate across the river basin polygon for the Eastern Cape in 36 CMIPs models for a the historical runs for the 1979-2005, b the mid-twentyfirst century projections (2040-2060) and $\mathbf{c}$ the difference between the mid-twenty-first century projections and the historical runs. 

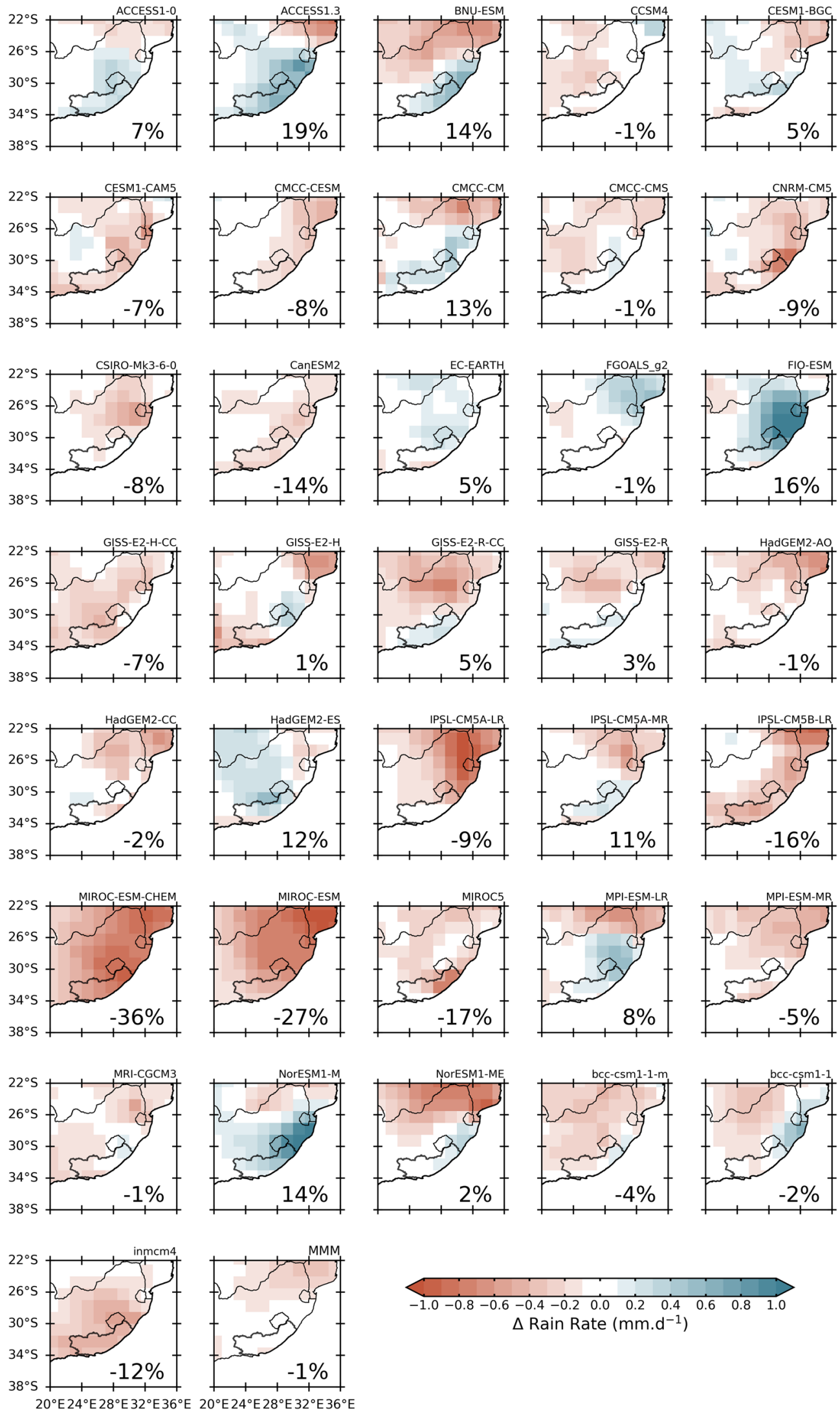
४Fig. 14 Mid-twenty-first century (2040-2060) projected changes in austral spring (SON) rainfall (shaded; in $\mathrm{mm}$ per day) in comparison to the historical period of 1976-2005 for the eastern half of South Africa in 36 CMIP5 models. The percentage change (\%) given in the right-hand corner of each panel denotes the change averaged across the polygon (charcoal line) across the Eastern Cape river basins. The multi-model mean (MMM) in given in the last panel

the summer. From Fig. 14 it is evident that most of the 36 models project drying in spring but since 8 models project wetter conditions, then when averaged across the province, the multi-model mean indicates only very slight drying in this season. However, given the complex topography and meteorology, highly varying soil and vegetation conditions in this province (e.g. 6 of the 7 biomes found in South Africa also occur in the Eastern Cape) together with the presence of the highly variable and intense Agulhas Current to its south, it is not surprising that the models should show a spread in projections over the Eastern Cape and have difficulties in accurately representing its climate. A substantial part of the difficulties that such models have with representing the region's climate likely results from their ability to adequately represent the characteristics of the cloud bands. As previously highlighted, changes in the frequency of cloud bands during SON can result in wetter (more cloud bands) or drier (fewer cloud bands) conditions in the Eastern Cape. In a comprehensive analysis of the ability of CMIP5 models to represent cloud bands over southern Africa, James et al. (2020) found that there are large variations in the modelled average locations and frequencies of these weather systems between the models even though all models correctly simulate the large scale generation and evolution of the cloud bands. Since the Eastern Cape is only part of the large area in southern Africa affected by cloud bands, small errors in the model simulations of cloud bands can therefore lead to substantial discrepancies in the resulting model simulation of seasonal rainfall. This large model spread in seasonal rainfall simulation means that future projections need to be viewed with caution and that the complex geography and meteorology of this region is likely to continue to pose significant challenges for climate models.

\section{Conclusions}

The Eastern Cape province of South Africa lies in the transition zone between the winter rainfall (western South Africa) and the summer rainfall (rest of subtropical southern Africa) regions which makes it an interesting but complex region to study. It is characterised by strong topographic, soil moisture and vegetation gradients and its coast is close to the highly variable Agulhas Current (the most intense western boundary current in the global oceans). Given its latitudinal range of about $30-34^{\circ} \mathrm{S}$, the Eastern Cape is influenced by both tropical and midlatitude weather systems and their interactions further adding to the complexity of its meteorology. Severe droughts and flooding events are frequently experienced in the Eastern Cape which cause substantial socioeconomic impacts, including loss of life in some cases. Currently, the province is suffering an intense drought (which started in 2015) with several urban areas under stringent water restrictions and having been close to have run out of piped water from the corresponding dams.

Although the 2015-drought has manifest itself throughout all seasons, focus here has been placed on spring (September-November) which shows the strongest and most coherent signal. On average, this season contributes between 25 and $35 \%$ of the annual total rainfall. A composite analysis of the 5 driest (wettest) springs since 1981 which are chosen on the basis that the extended summer are also anomalously dry (wet) indicated that these were related to a large cyclonic (anticyclonic) mid-tropospheric anomaly located to the south and southeast of South Africa that seems in turn to be related to changes in the zonal wavenumber 3 pattern. Over southern Africa, the composites suggest that dry (wet) springs are associated with a weaker (stronger) near-surface Angola Low and stronger (weaker) mid-level Botswana High with enhanced (reduced) subsidence which lead to less (more) favourable conditions for cloud bands to develop. None of the large-scale climate modes that are known to affect subtropical southern Africa show statistically significant correlations with spring rainfall over the Eastern Cape but the Southern Annular Mode is significantly correlated (positive) with summer rainfall.

Trends in spring rainfall characteristics were also investigated. Most of the Eastern Cape shows a statistically significant decline in spring rainfall, particularly in the east and northeast of the province. This east/northeastern region is in fact part of a larger region of eastern South Africa (with strongest trends in this part of the Eastern Cape, Lesotho and eastern Free State) (not shown) which shows significant decreasing trends in spring rainfall totals and rain days. Elsewhere, part of the dam catchment areas for the largest city of Port Elizabeth also show significantly decreasing trends. Overall, the results suggest that the rainfall gradient across the province is weakening, at least in spring. Most of the decreasing rainfall trend seems to result from a reduction in the number of rainfall days but not in heavy rainfall days (defined as more than $>10 \mathrm{~mm}$ per day).

Analysis of mid-century (2040-2060) projections under the RCP8.5 scenario suggested that there may be a slight flattening of the annual cycle over the Eastern Cape with the winter becoming wetter and the summer drier. For the spring season of interest here, the multi-model projections also indicated drying but less pronounced than for the summer. Although most of the 36 models analysed project a spring drying over the Eastern Cape, the multi-model mean 
indicates only very slight drying in this season. However, given the strong land and ocean surface gradients in the region and its sensitivity to both tropical and midlatitude circulation, it is not surprising that the models should show a spread in projections over the Eastern Cape and have difficulties in accurately representing its climate. Furthermore, the difficulties relative to observations that CMIP5 models have in simulating the frequency and location of cloud bands (James et al. 2020), a key rainfall-producing system over the region, adds to the uncertainty in future rainfall changes. Caution therefore needs to be taken regarding future projections over this region. Nonetheless, the complex geography and meteorology of this region does provide an interesting test bed for climate models.

Acknowledgements The first author gratefully acknowledges the South African National Antarctic Programme of the NRF for partially funding her $\mathrm{PhD}$ research. The authors thank the South African Weather Service (SAWS) for providing rainfall data and Pierre Kloppers (CSAG, UCT) for assistance with data quality control. NCEP and OISST data were obtained from the NOAA/ESRL Physical Sciences Division, Boulder Colorado website at https://www.esrl.noaa.gov/psd/. Daily CHIRPS data have been downloaded from the Climate Hazards Group data website (https://www.chc.ucsb.edu/data/chirps). The Nino 3.4 index, SAM index and SIOD were downloaded from the KNMI Climate Explorer (https://climexp.knmi.nl). We also acknowledge the World Climate Research Programme's Working Group on Coupled Modelling responsible for CMIP5 model data, which was provided by the Program for Climate Model Diagnosis and Intercomparison (PCMDI; https://pcmdi.llnl.gov/).

\section{References}

Adler RF, Huffman GJ, Chang A, Ferraro R, Xie P-P, Janowiak J, Rudolf B, Schneider U, Curtis S, Bolvin D (2003) The version-2 global precipitation climatology project (GPCP) monthly precipitation analysis (1979-present). J Hydrometeorol 4(6):1147-1167

Behera SK, Yamagata T (2001) Subtropical SST dipole events in the southern Indian Ocean. Geophys Res Lett 28(2):327-330

Blamey R, Reason CJC (2009) Numerical simulation of a mesoscale convective system over the east coast of South Africa. Tellus A Dyn Meteorol Oceanogr 61:17-34

Blamey R, Reason CJC (2013) The role of mesoscale convective complexes in southern Africa summer rainfall. J Clim 26:1654-1668

Blamey RC, Kolusu S, Mahlalela P, Todd M, Reason CJC (2018a) The role of regional circulation features in regulating El Niño climate impacts over southern Africa: a comparison of the 2015/2016 drought with previous events. Int J Climatol 38:4276-4295

Blamey RC, Ramos AM, Trigo R, Tomé R, Reason CJC (2018b) The influence of atmospheric rivers over the South Atlantic on winter rainfall in South Africa. J Hydrometeorol 19:127-142

Botai CM, Botai JO, Adeola AM (2018) Spatial distribution of temporal precipitation contrasts in South Africa. S Afr J Sci 114:70-78

Burls NJ, Blamey RC, Cash BA, Swenson ET, al Fahad A, Bopape M-JM, Straus DM, Reason CJC (2019) The Cape Town "Day Zero" drought and Hadley cell expansion. NPJ Clim Atmos Sci 2(1): $1-8$

Cook C, Reason CJC, Hewitson BC (2004) Wet and dry spells within particularly wet and dry summers in the South African summer rainfall region. Clim Res 26(1):17-31
Diab R, Preston-Whyte R, Washington R (1991) Distribution of rainfall by synoptic type over Natal, South Africa. Int J Climatol 11:877-888

Driver P, Reason CJC (2017) Variability in the Botswana High and its relationships with rainfall and temperature characteristics over southern Africa. Int J Climatol 37:570-581

Engelbrecht CJ, Landman WA (2016) Interannual variability of seasonal rainfall over the Cape south coast of South Africa and synoptic type association. Clim Dyn 47:295-313

Engelbrecht CJ, Landman WA, Engelbrecht FA, Malherbe J (2015) A synoptic decomposition of rainfall over the Cape south coast of South Africa. Clim Dyn 44:2589-2607

Fauchereau N, Pohl B, Reason CJC, Rouault M, Richard Y (2009) Recurrent daily OLR patterns in the Southern Africa/Southwest Indian Ocean region, implications for South African rainfall and teleconnections. Clim Dyn 32(4):575-591

Funk C, Peterson P, Landsfeld M, Pedreros D, Verdin J, Shukla S, Husak G, Rowland J, Harrison L, Hoell A, Michaelsen J (2015) The climate hazards infrared precipitation with stations-a new environmental record for monitoring extremes. Sci Data 2:150066

Gillett NP, Kell TD, Jones PD (2006) Regional climate impacts of the Southern Annular Mode. Geophys Res Lett 33:L23704. https:// doi.org/10.1029/2006GL027721

Hansingo K, Reason CJC (2009) Modelling the atmospheric response over southern Africa to SST forcing in the southeast tropical Atlantic and southwest subtropical Indian Oceans. Int J Climatol 29(7):1001-1012

Harrison MSJ (1984) A generalized classification of South African summer rain-bearing synoptic systems. J Climatol 4:547-560

Hart N, Reason CJC, Fauchereau N (2010) Tropical-extratropical interactions over southern Africa: three cases of heavy summer season rainfall. Mon Weather Rev 138:2608-2623

Hart NCG, Reason CJC, Fauchereau N (2012) Building a tropicalextratropical cloud band metbot. Mon Weather Rev 140:40054016. https://doi.org/10.1175/MWR-D-12-00127.1

Hart NCG, Washington R, Reason CJC (2018) On the likelihood of tropical-extratropical cloud bands in the South Indian Convergence Zone during ENSO events. J Clim 31:2797-2817

IPCC (2013) Climate change 2013: the physical science basis. contribution of working group $i$ to the fifth assessment report of the intergovernmental panel on climate change. In: Stocker TF, Qin D, Plattner G-K, Tignor M, Allen SK, Boschung J, Nauels A, Xia Y, Bex V, Midgley PM (eds) Cambridge University Press, Cambridge, United Kingdom and New York, NY, USA, 1535 pp

James R, Hart N, Munday C, Reason CJC, Washington R (2020) Coupled climate model simulation of tropical-extratropical cloud bands over southern Africa. J Clim. https://doi.org/10.1175/JCLID-19-0731.s1 (in press)

Jury MR, Valentine HR, Lutjeharms JRE (1993) Influence of the agulhas current on summer rainfall along the southeast coast of SouthAfrica. J Appl Meteorol 32:1282-1287

Kanamitsu M, Ebisuzaki W, Woollen J, Yang S-K, Hnilo J, Fiorino M, Potter G (2002) NCEP-DOE AMIP-ii reanalysis (r-2). Bull Am Meteorol Soc 83:1631-1644

Lindesay J (1988) South African rainfall, the Southern Oscillation and a Southern Hemisphere semi-annual cycle. J Climatol 8(1):17-30

Mahlalela P, Blamey RC, Reason CJC (2019) Mechanisms behind early winter rainfall variability in the southwestern Cape, South Africa. Clim Dyn 53:21-39

Manhique A, Reason CJC, Rydberg L, Fauchereau N (2011) ENSO and Indian Ocean sea surface temperatures and their relationships with tropical temperate troughs over Mozambique and the Southwest Indian Ocean. Int J Climatol 31:1-13

Marshall GJ (2003) Trends in the Southern Annular Mode from observations and reanalyses. J Clim 16:4134-4143 
Mason S (1995) Sea-surface temperature-South African rainfall associations 1910-1989. Int J Climatol 15:119-135

Mulenga H, Rouault M, Reason C (2003) Dry summers over northeastern South Africa and associated circulation anomalies. Clim Res 25:29-41

Pienaar L, Boonzaaier J (2018) Drought policy brief Western Cape Agriculture. Western Cape Department of Agriculture (WCDoA) and the Bureau for Food and Agricultural Policy (BFAP), Elsenburg

Raphael MN (2004) A zonal wave number 3 index for the Southern Hemisphere. Geophys Res Lett 31:L23212. https://doi. org/10.1029/2004GL020365

Reason CJC (1999) Interannual warm and cool events in the subtropi$\mathrm{cal} /$ mid-latitude South Indian Ocean region. Geophys Res Lett 26:215-218

Reason CJC (2001) Subtropical Indian Ocean SST dipole events and southern African rainfall. Geophys Res Lett 28(11):2225-2227

Reason CJC (2016) The Bolivian, Botswana, and Bilybara Highs and Southern Hemisphere drought/floods. Geophys Res Lett 43(3):1280-1286

Reason CJC, Mulenga H (1999) Relationships between South African rainfall and SST anomalies in the southwest Indian Ocean. Int J Climatol 19(15):1651-1673

Reason CJC, Rouault M (2005) Links between the Antarctic Oscillation and winter rainfall over western South Africa. Geophys Res Lett 32:1-4. https://doi.org/10.1029/2005GL022419

Reason CJC, Allan RJ, Lindesay JA, Ansell TJ (2000) ENSO and climatic signals across the Indian Ocean basin in the global context: part I, Interannual composite patterns. Int J Climatol 20(11):1285-1327

Reason CJC, Rouault M, Melice J-L, Jagadheesha D (2002) Interannual winter rainfall variability in SW South Africa and large scale ocean-atmosphere interactions. Meteorol Atmos Phys 80(1-4):19-29

Rouault M, White S, Reason CJC, Lutjeharms J, Jobard I (2002) Ocean-atmosphere interaction in the Agulhas Current region and a South African extreme weather event. Weather Forecast 17(4):655-669

Rouault M, Florenchie P, Fauchereau N, Reason CJ (2003) South East tropical Atlantic warm events and southern African rainfall. Geophys Res Lett 30(5):8009. https://doi.org/10.1029/2002GL014840
Saji N, Goswami B, Vinayachandran P, Yamagata T (1999) A dipole mode in the tropical Indian Ocean. Nature 401(6751):360-363

Singleton AT, Reason CJC (2006) Numerical Simulations of a Severe Rainfall Event over the Eastern Cape coast of South Africa: sensitivity to sea surface temperature and topography. Tellus A 58(3):355-367

Singleton A, Reason CJC (2007a) A numerical model study of an intense cut-off low pressure system over South Africa. Mon Weather Rev 135:1128-1150

Singleton A, Reason CJC (2007b) Variability in the characteristics of cut-off low pressure systems over subtropical southern Africa. Int J Climatol 27:295-310

Sousa PM, Blamey RC, Reason CJC, Ramos AM, Trigo RM (2018) The 'Day Zero' Cape Town drought and the poleward migration of moisture corridors. Environ Res Lett 13:124025

Taljaard JJ (1985) Cut-off lows in the South African region. Weather Bureau, Department of Transport., 1996: Atmospheric circulation systems, synoptic climatology and weather phenomena of South Africa. Part 6, Rainfall in South Africa. Department of Environmental Affairs and Tourism

Taylor KE, Stouffer RJ, Meehl GA (2012) An overview of CMIP5 and the experiment design. Bull Am Meteorol Soc 93(4):485-498

Todd M, Washington R (1999) Circulation anomalies associated with tropical-temperate troughs in southern Africa and the south west Indian Ocean. Clim Dyn 15(12):937-951

Walker N (1990) Links between South African summer rainfall and temperature variability of the Agulhas and Benguela Current systems. J Geophys Res Oceans 95(C3):3297-3319

Weldon D, Reason CJC (2014) Variability of rainfall characteristics over the South Coast region of South Africa. Theor Appl Climatol 115(1-2):177-185

Xie P, Arkin PA (1997) Global precipitation: a 17-year monthly analysis based on gauge observations, satellite estimates, and numerical model outputs. Bull Am Meteorol Soc 78(11):2539-2558

Publisher's Note Springer Nature remains neutral with regard to jurisdictional claims in published maps and institutional affiliations. 